\title{
Genetic diversity, population structure and marker-trait associations for agronomic and grain traits in wild diploid wheat Triticum urartu
}

Xin Wang ${ }^{1,2}$, Guangbin Luo ${ }^{1,2}$, Wenlong Yang ${ }^{1}$, Yiwen Li ${ }^{1}$, Jiazhu Sun ${ }^{1}$, Kehui Zhan ${ }^{3}$, Dongcheng Liu ${ }^{1 *}$ (D) and Aimin Zhang ${ }^{1,3^{*}}$

\begin{abstract}
Background: Wild diploid wheat, Triticum urartu (T. urartu) is the progenitor of bread wheat, and understanding its genetic diversity and genome function will provide considerable reference for dissecting genomic information of common wheat.

Results: In this study, we investigated the morphological and genetic diversity and population structure of $238 \mathrm{~T}$. urartu accessions collected from different geographic regions. This collection had 19.37 alleles per SSR locus and its polymorphic information content (PIC) value was 0.76 , and the PIC and Nei's gene diversity (GD) of high-molecularweight glutenin subunits (HMW-GSs) were 0.86 and 0.88 , respectively. UPGMA clustering analysis indicated that the 238 T. urartu accessions could be classified into two subpopulations, of which Cluster I contained accessions from Eastern Mediterranean coast and those from Mesopotamia and Transcaucasia belonged to Cluster II. The wide range of genetic diversity along with the manageable number of accessions makes it one of the best collections for mining valuable genes based on marker-trait association. Significant associations were observed between simple sequence repeats (SSR) or HMW-GSs and six morphological traits: heading date (HD), plant height (PH), spike length $(\mathrm{SPL})$, spikelet number per spike (SPLN), tiller angle (TA) and grain length (GL).

Conclusions: Our data demonstrated that SSRs and HMW-GSs were useful markers for identification of beneficial genes controlling important traits in T. urartu, and subsequently for their conservation and future utilization, which may be useful for genetic improvement of the cultivated hexaploid wheat.
\end{abstract}

Keywords: Triticum urartu, Genetic diversity, SSR markers, HMW-GS, Marker-trait association

\section{Background}

Bread wheat (Triticum aestivum L.) is one of the most important crops in the world, providing about $20 \%$ of the calories consumed globally (FAOSTAT 2011; http:// faostat.fao.org/). To meet the world's growing demand for food, it is urgent to develop high yielding varieties with good end-product making quality [1]. A better understanding of the genetic basis of yield and its

\footnotetext{
* Correspondence: dcliu@genetics.ac.cn; amzhang@genetics.ac.cn

'State Key Laboratory of Plant Cell and Chromosome Engineering, National

Center for Plant Gene Research, Institute of Genetics and Developmental

Biology, Chinese Academy of Sciences, 1 West Beichen Road, Chaoyang

District, Beijing 100101, China

Full list of author information is available at the end of the article
}

components is a pre-requisite, though genomic research in bread wheat remains a major challenge because of the complexity associated with its hexaploid structure and huge genome size $[2,3]$. Wild diploid wheat, $T$. urartu $(2 \mathrm{n}=2 \times=14 ; \mathrm{AA})$, the A-genome donor of cultivated tetraploid $(2 \mathrm{n}=4 \times=28$; genome $\mathrm{AABB})$ and hexaploid wheat $(2 \mathrm{n}=6 \times=42$; AABBDD) [4], played an important role in the development and evolution of cultivated bread wheat. With the available reference genome [5], it is more feasible to exploit T. urartu as the reference sub-genome of common wheat, which will obviously provide considerable valuable information for the improvement of the latter. 
Although T. urartu possesses the A genome in common with bread wheat, its genetic diversity has not been well investigated as Einkorn wheat (T. monococcum), another diploid progenitor [6]. Nowadays, the genetic diversity within wheat cultivars has been drastically reduced in the process of domestication and breeding $[7,8]$, and it is essential to apply new contributing genes for wheat improvement. As a wild diploid progenitor of hexaploid wheat, T. urartu harbors rich allelic diversity for numerous important traits, including agronomic characteristics, grain quality and biotic stress tolerance [9-11]. Genetic variation of T. urartu has been investigated using various markers such as isozyme, restriction fragment length polymorphism (RFLP), amplified fragment length polymorphism (AFLP), and random amplified polymorphic DNA (RAPD) markers [12-16]. Such genetic diversities can be exploited to elucidate the genetic basis of natural variation of important quantitative traits. Hence, more accessions widespread should be employed to provide a more comprehensive on the characteristic of the whole population.

Most agronomic traits in common wheat, such as yield and its components, dough quality and resistant characters, are controlled by multiple genes and influenced substantially by the environment, which hinders the dissection of their genetic basis [17]. Classical linkage mapping based on bi-parental populations was a conventional approach to dissect the genetic bases of complex traits [18]. Various studies have identified a set of major effect quantitative trait loci (QTL) for important agronomic traits in wheat, such as kernel weight and dough quality $[17,19-24]$. As an alternative way to QTL mapping, association mapping uses diverse material to associate genetic markers with a phenotype of interest, which presents higher mapping resolution of the phenotypes at a population level [25]. It has been exploited successfully to identify genomic regions contributing to numerous traits in diverse crops, such as maize [26, 27], rice [28], sorghum [29] and soybean [30]. There is increasing interests in identifying novel marker-trait associations using association mapping in wheat $[31,32]$. For example, Breseghello and Sorrells [17] found significant associations between some simple sequence repeats (SSR) markers and wheat kernel traits, including weight, length and width of kernels.

The objectives of this study were to investigate the genetic diversity, population structure and relationships among a collection of $238 \mathrm{~T}$. urartu accessions collected from the Fertile Crescent region and to identify marker loci associated with important agronomic and grain traits. Our results would provide further insights into the utility of association mapping for marker-assisted selection and its potential application in bread wheat breeding.

\section{Methods}

\section{Plant material}

A total of $238 T$. urartu accessions, which covered most of the original areas, were subjected to SSR and highmolecular-weight glutenin subunits (HMW-GS) analysis with SDS-PAGE. This panel was obtained from the Institute of Genetics and Developmental Biology, Chinese Academy of Sciences (IGDB, CAS), the National Small Grain collection (USDA-ARS) and the International Center for Agricultural Research in the Dry Areas (ICARDA). Among these accessions, 84 were originated from Lebanon, 80 from Turkey, 37 from Syria, 12 from Armenia, 11 from Jordan, 11 from Iran, and three from Iraq (Fig. 1; Additional file 1: Table S1).

\section{Field experiment and phenotyping}

The collected $T$. urartu accessions were planted at the experimental station of the Institute of Genetics and Developmental Biology, Chinese Academy of Sciences, Beijing $\left(40^{\circ} 5^{\prime} 56^{\prime \prime} \mathrm{N}\right.$ and $\left.116^{\circ} 25^{\prime} 8^{\prime \prime} \mathrm{E}\right)$, that of Henan Agricultural University, Zhengzhou (34⒌ $\left.52^{\prime \prime} \mathrm{N}, 113^{\circ} 35^{\prime} 45^{\prime \prime} \mathrm{E}\right)$ and that of Dezhou Academy of Agricultural Sciences, Dezhou $\left(37^{\circ} 45^{\prime} 69^{\prime \prime} \mathrm{N}, 116^{\circ} 30^{\prime} 23^{\prime \prime} \mathrm{E}\right)$ in two consecutive years (2013-2014 and 2014-2015 cropping seasons). These environments were designated as E1 (Beijing, 2013), E2 (Zhengzhou, 2013), E3 (Dezhou, 2013), E4 (Beijing, 2014), E5 (Zhengzhou, 2014), and E6 (Dezhou, 2014), respectively.

Each field trial was managed in a completely randomized block design with two replications. All the plants were grown in a single $2-\mathrm{m}$ row with $40 \mathrm{~cm}$ between rows and $20 \mathrm{~cm}$ between individuals. Nine traits were evaluated and analyzed, including heading date (HD), plant height $(\mathrm{PH})$, spike length (SPL), spikelet number per spike (SPLN), tiller angle (TA), grain length (GL), grain width $(\mathrm{GW})$, grain length/width ratio (GLW) and thousand-grain weight (TGW). The HD was counted as days from sowing to heading, and the date of heading was subsequently recorded when half of the spikes emerged from the flag leaf in each accession. The TA was measured between the last developed tillers and the ground level with a protractor at the maximum tillering stage, while the other agronomic traits were determined on the primary tiller. After the harvest, a minimum of 200 grains from each sample was photographed on a flat-bed scanner and the images were obtained as the aerial view of the ventral side of the grains. The GL, GW and GLW were calculated using the grain analyzer software (SC-G Scanner, Wanshen Detection Technology Inc., Hangzhou, China), and the TGW was measured by the average of two 1000 kernel-weights.

\section{DNA isolation and nested-PCR amplification}

Genomic DNA was isolated from young leaf tissue of two-week-old seedlings (one individual per accession) 


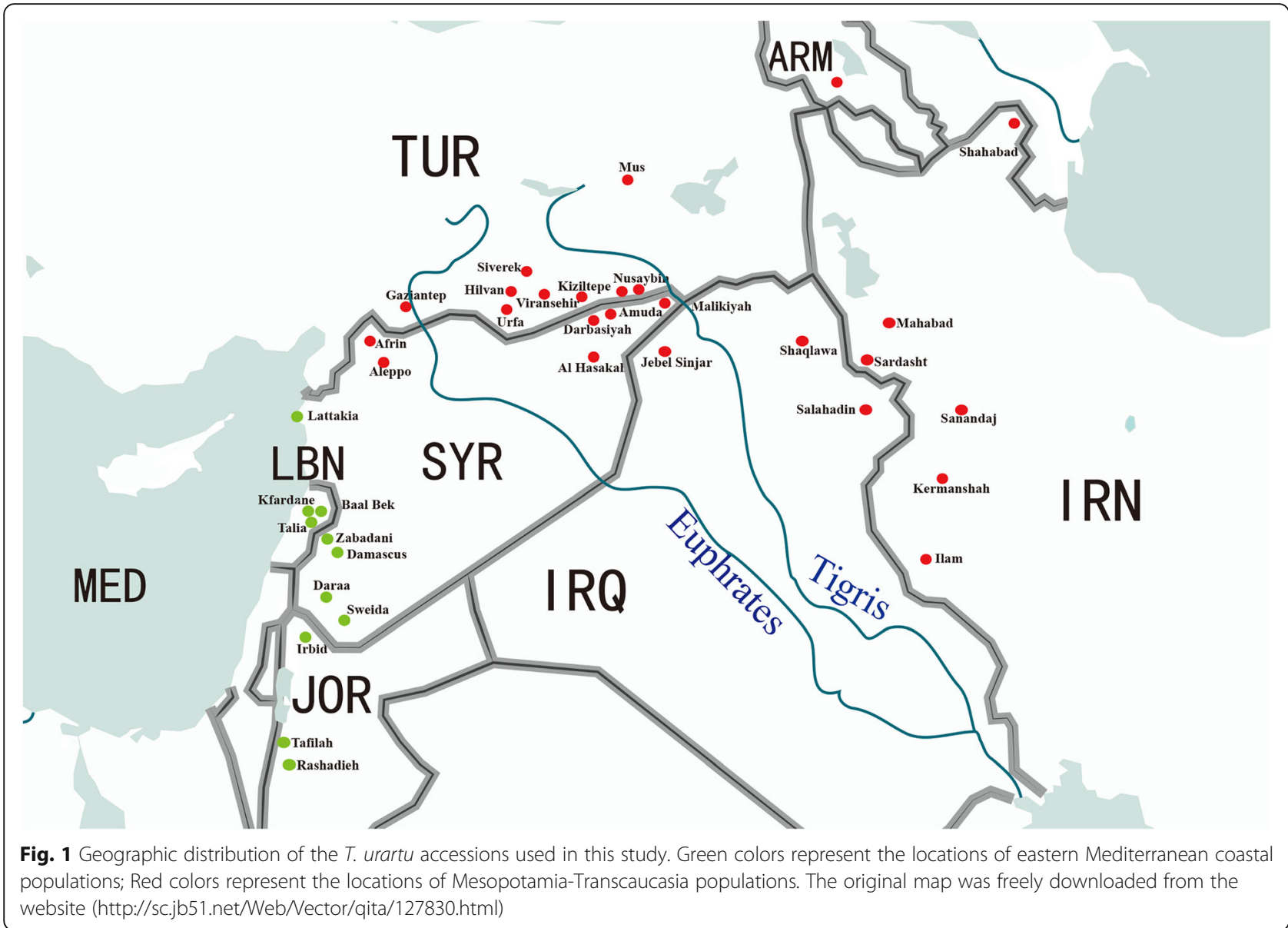

using the cetyl trimethyl ammonium bromide (CTAB) method [33]. DNA concentration was determined and diluted to a working solution of $50 \mathrm{ng} / \mu \mathrm{L}$. Primer sequences of 62 SSR markers (Additional file 1: Table S2) used in this experiment were obtained from the GrainGenes database (https://wheat.pw.usda.gov/cgibin/graingenes/browse.cgi?class=marker). The nestedPCR amplifications were performed using fluorescent dye labeling system according to Schuelke [34]. In brief, amplification reactions were performed in a final volume of $15 \mu \mathrm{L}$, containing $3 \mu \mathrm{L}$ template DNA, $0.2 \mu \mathrm{L}$ forward primer with the M13 tail at its $5^{\prime}$-end $(2.0 \mu \mathrm{M}), 1.0 \mu \mathrm{L}$ M13 primer (labeled with 6-FAM, NED, VIC or PET), $1.2 \mu \mathrm{L}$ reverse primer $(2.0 \mu \mathrm{M})$, $7.5 \mu \mathrm{L}$ Mix-Taq (CWBIO, China) and $2.1 \mu \mathrm{L} \mathrm{H}_{2} \mathrm{O}$ (CWBIO, China). PCR was performed as follows: initial denaturing at $95{ }^{\circ} \mathrm{C}$ for $4 \mathrm{~min}, 15$ cycles of $94{ }^{\circ} \mathrm{C}$ for $30 \mathrm{~s}, 60{ }^{\circ} \mathrm{C}$ for $45 \mathrm{~s}$, and $72{ }^{\circ} \mathrm{C}$ for $45 \mathrm{~s}$, followed by 25 cycles of $95{ }^{\circ} \mathrm{C}$ for $30 \mathrm{~s}, 52{ }^{\circ} \mathrm{C}$ for $45 \mathrm{~s}, 72{ }^{\circ} \mathrm{C}$ for $45 \mathrm{~s}$, and a final extension at $72{ }^{\circ} \mathrm{C}$ for $10 \mathrm{~min}$. All reactions were conducted using a thermal cycler, Veriti 96 (Applied Biosystems, Foster City, USA).

Amplified PCR products were pooled and then purified with $3.0 \mathrm{M}$ sodium acetate and $70 \%$ ethanol before adding HiDi-formamide. Fluorescently labeled DNA fragments were separated by capillary electrophoresis in an ABI 3730xlDNA Analyzer with GeneScan-500 LIZ size standard (Applied Biosystems, Foster City, CA, USA). SSR polymorphism was analyzed by GeneMapper software version 4.0 (Applied Biosystems, Foster City, CA, USA) according to the manufacturer's instructions.

\section{Protein extraction and SDS-PAGE analysis}

In each accession, the HMW-GS proteins were extracted from three seeds according to previous procedure [35], and SDS-PAGE was performed to fractionate the HMW-GSs using 10\% $(w / v)$ separating and 3\% $(w / v)$ stacking gels. Electrophoresis was conducted at a constant current of $18 \mathrm{~mA}$ at room temperature for about $8 \mathrm{~h}$, and then the SDS-PAGE gels were stained overnight with Coomassie Brilliant Blue G-250 in a solution containing 20\% $(v / v)$ methanol and 10\% $(v / v)$ acetic acid. De-staining was carried out with tap water and then the gels were subjected to image capturing on a highresolution scanner (GE ImageScanner III). The identification of HMW-GSs and alleles were based on the methodology described by [36]. 


\section{Genetic diversity and phylogenetic analysis}

For 62 SSR polymorphic loci, the genetic parameters of variability were estimated via the POPGENE1.32 software [37], including number of observed (Ao) and expected (Ae) alleles per locus, observed (Ho) and expected (He) heterozygosity, Shannon's information index (I), Nei's Gene diversity (GD) and Polymorphism information content (PIC). The accuracy of these genotyping data was also manually checked for the scoring errors and null alleles using the Micro-Checker software [38]. All the parameters were computed for both the whole collection and the subsets considering their geographic origin and population structure category. Genetic distance and phylogenetic analyses of $T$. urartu accessions were conducted based on the Jaccard's coefficient similarity matrix obtained from the proportion of shared SSR fragments and HMW-GS bands, then a dendrogram was drawn with NTSYSpc 2.11 program [39] using UPGMA algorithm. The fitness of the dendrogram was assessed by bootstrap analysis running 1000 replications.

\section{Population structure}

The model-based (Bayesian) STRUCTURE version 2.3.1 was applied to identify clusters of genetically similar individuals on the basis of their genotypes [40]. The program was run five times independently for $K$ value (number of subpopulations) ranging from 1 to 15, adopting the admixture model and correlated allele frequencies, with a burn-in period of 50,000 and the number of replications at 100,000. The normal logarithm of the probability was calculated against each $K$ value, and the optimal number of subpopulations was determined using the $\Delta K$ approach described by Evanno et al. [41]. Then each $T$. urartu individuals could be assigned to the putative subpopulations according to their average membership coefficient, which was calibrated using CLUMPP $[42,43]$. A nested analysis of population structure with the same software and parameters was carried out to distinguish the next level of subpopulations.

\section{Analysis of molecular variance (AMOVA)}

Analysis of molecular variance (AMOVA) was performed to estimate the genetic variance within and among inferred populations in $T$. urartu accessions. Population differentiation was assessed by calculating pairwise Fst values and Nei's genetic distances for different regional population pairs. The threshold for statistical significance was determined by running 10,000 permutations. Principal coordinate analysis (PCoA) was also carried out based on binary genetic distance. The generated eigenvalues and accumulated percentage of the variation were applied to plot the scatter diagram of these representative accessions, with the first two principal coordinates which accounted for the highest variation. All the calculations mentioned above were implemented in the GenAlex 6.5 software [44].

\section{Association analysis}

The markers with minor allele frequency less than 5\% were removed in order to reduce false positive associations. The pairwise kinship (K matrix) among samples was generated from the program SPAGeDi [45]. Linkage disequilibrium estimates for each pair of loci and marker-trait association analysis were conducted using TASSEL 2.1 software [46], via a general linear model (GLM) and a mixed linear model (MLM). In GLM model, population structure of the $T$. urartu mapping panel was included as fixed effects, while association was estimated by simultaneous accounting of multiple levels of population structure (Q matrix) and relative kinship among the individuals (K matrix) in MLM. The significant threshold for associations between loci and traits was set at $P<0.01$. The Bonferroni correction of multiple testing was performed based on the q value using false discovery rate (FDR, $\left.\alpha_{c}=0.05\right)$. For all associated markers, the average phenotypic effects of different alleles were estimated using the method proposed by Breseghello and Sorrells [17].

\section{Results}

\section{Phenotypic variation and correlations among traits}

The phenotypic data of investigated traits across the six environments, including mean values, minimum and maximum values, standard deviations and the heritability estimates $\left(h^{2}\right)$, were calculated (Table 1 ). The data revealed a broad variation for all traits in these $T$. urartu accessions, e.g. PH had an average of $112.43 \mathrm{~cm}$ (minimum $86.10 \mathrm{~cm}$ and maximum $149.10 \mathrm{~cm}$ ) with $12.23 \mathrm{~cm}$ standard deviation in E1, and TGW ranged from 4.29 to $18.87 \mathrm{~g}$ with $2.96 \mathrm{~g}$ standard deviation in E5. The phenotypic data for HD, PH, SPL, SPLN, GL, GW, GLW and TGW followed the normal distribution, suggesting that these traits were controlled by multiple loci. The broad-sense heritability $\left(h^{2}\right)$ of all the traits was relatively high, ranging from $68.91 \%$ for TA (E2) to 94.05\% for SPLN (E4), which confirmed that most of the phenotypic variance was genetically determined. Moreover, significant correlations coefficients among different environments were also detected, implying the less genotype $\mathrm{x}$ environment interactions of these traits (Additional file 1: Table S3). Depending on the collection site, all of the T. urartu accessions could be roughly split as Eastern Mediterranean coastal and MesopotamiaTranscaucasia group, and the details of phenotypic performances illustrated that most of the traits investigated in this study differed greatly between the two major subsets (Additional file 1: Table S4). 
Table 1 Phenotypic performances and distribution parameters for the investigated traits of 238 T. urartu accessions in six environments

\begin{tabular}{|c|c|c|c|c|c|c|}
\hline Trait & Env. ${ }^{a}$ & Mean ${ }^{b}$ & Min. ${ }^{c}$ & Max. ${ }^{d}$ & $S D^{e}$ & $h^{2}(\%)^{t}$ \\
\hline $\mathrm{HD}$ & E1 & 207.43 & 196.00 & 229.00 & 8.57 & 78.18 \\
\hline \multirow[t]{5}{*}{ Heading date (days) } & E2 & 205.45 & 192.00 & 225.00 & 8.85 & 82.36 \\
\hline & E3 & 200.42 & 182.00 & 218.00 & 9.22 & 80.54 \\
\hline & E4 & 216.57 & 204.00 & 239.00 & 8.89 & 83.77 \\
\hline & E5 & 208.16 & 195.00 & 228.00 & 10.15 & 78.95 \\
\hline & E6 & 209.05 & 199.00 & 227.00 & 8.06 & 81.14 \\
\hline $\mathrm{PH}$ & E1 & 112.43 & 86.10 & 149.10 & 12.23 & 76.43 \\
\hline \multirow[t]{5}{*}{ Plant height (cm) } & E2 & 117.02 & 82.70 & 151.40 & 13.68 & 73.82 \\
\hline & E3 & 116.34 & 89.00 & 154.60 & 15.25 & 75.47 \\
\hline & E4 & 122.58 & 92.33 & 157.00 & 14.07 & 79.15 \\
\hline & E5 & 116.70 & 92.66 & 148.00 & 10.87 & 78.56 \\
\hline & E6 & 106.64 & 67.67 & 136.00 & 12.24 & 72.84 \\
\hline SPL & E1 & 11.10 & 7.38 & 14.92 & 1.62 & 87.22 \\
\hline \multirow[t]{5}{*}{ Spike length (cm) } & E2 & 13.02 & 7.02 & 18.43 & 2.31 & 86.61 \\
\hline & E3 & 11.19 & 5.00 & 16.03 & 2.05 & 84.89 \\
\hline & E4 & 13.09 & 9.00 & 18.67 & 2.07 & 89.27 \\
\hline & E5 & 12.52 & 8.38 & 16.90 & 2.00 & 87.33 \\
\hline & E6 & 10.63 & 7.30 & 14.80 & 1.65 & 89.06 \\
\hline SPLN & E1 & 27.29 & 19.20 & 36.00 & 3.76 & 92.73 \\
\hline \multirow[t]{5}{*}{ Spikelet number/spike } & E2 & 29.96 & 20.00 & 41.70 & 4.32 & 91.46 \\
\hline & E3 & 27.95 & 20.20 & 39.30 & 4.09 & 90.94 \\
\hline & E4 & 32.44 & 23.00 & 49.50 & 5.11 & 94.05 \\
\hline & E5 & 26.96 & 17.00 & 38.70 & 4.32 & 92.55 \\
\hline & E6 & 26.34 & 16.80 & 36.00 & 3.70 & 89.49 \\
\hline TA & E2 & 60.43 & 25.00 & 72.00 & 15.29 & 68.91 \\
\hline \multirow[t]{2}{*}{ Tiller angle $\left(^{\circ}\right)$} & E4 & 65.14 & 33.00 & 78.00 & 17.60 & 70.87 \\
\hline & E5 & 59.32 & 28.00 & 75.00 & 12.59 & 71.53 \\
\hline GL & E1 & 6.87 & 5.11 & 8.39 & 0.61 & 90.65 \\
\hline \multirow[t]{5}{*}{ Grain length (mm) } & E2 & 7.52 & 6.16 & 8.95 & 0.55 & 87.46 \\
\hline & E3 & 6.96 & 5.17 & 8.48 & 0.62 & 89.08 \\
\hline & E4 & 7.39 & 5.46 & 8.52 & 0.51 & 90.41 \\
\hline & E5 & 7.41 & 6.04 & 8.58 & 0.55 & 88.70 \\
\hline & E6 & 7.56 & 6.07 & 9.24 & 0.58 & 87.16 \\
\hline GW & E1 & 1.58 & 1.05 & 2.07 & 0.21 & 88.78 \\
\hline \multirow[t]{5}{*}{ Grain width (cm) } & E2 & 1.80 & 1.32 & 2.28 & 0.22 & 90.52 \\
\hline & E3 & 1.58 & 1.12 & 2.04 & 0.21 & 89.67 \\
\hline & E4 & 1.74 & 1.22 & 2.23 & 0.19 & 91.33 \\
\hline & E5 & 1.78 & 1.41 & 2.11 & 0.20 & 89.29 \\
\hline & E6 & 1.77 & 1.33 & 2.24 & 0.17 & 87.06 \\
\hline GLW & E1 & 4.49 & 3.51 & 5.71 & 0.40 & 88.49 \\
\hline \multirow[t]{4}{*}{ Grain length/width ratio } & E2 & 4.26 & 3.50 & 5.19 & 0.41 & 86.95 \\
\hline & E3 & 4.49 & 3.76 & 5.55 & 0.41 & 89.42 \\
\hline & E4 & 4.37 & 3.55 & 5.47 & 0.42 & 90.13 \\
\hline & E5 & 4.26 & 3.69 & 5.05 & 0.35 & 88.35 \\
\hline
\end{tabular}


Table 1 Phenotypic performances and distribution parameters for the investigated traits of 238 T. urartu accessions in six environments (Continued)

\begin{tabular}{lllllll}
\hline & E6 & 4.37 & 3.69 & 5.04 & 0.38 & 87.29 \\
TGW & E1 & 7.86 & 2.28 & 15.61 & 2.86 & 81.03 \\
Thousand-grain weight (g) & E2 & 11.43 & 5.15 & 21.84 & 3.10 & 83.80 \\
& E3 & 8.12 & 1.73 & 15.32 & 2.81 & 78.38 \\
& E4 & 10.26 & 2.50 & 15.40 & 2.41 & 85.11 \\
& E5 & 10.06 & 4.29 & 18.87 & 82.04 \\
& E6 & 9.77 & 3.91 & 18.23 & 2.64 & 81.90 \\
\hline
\end{tabular}

a Environment: E1, E2, E3, E4, E5 and E6 represent Beijing 2013, Zhengzhou 2013, Dezhou 2013, Beijing 2014, Zhengzhou 2014 and Dezhou 2014, respectively

${ }^{b}$ Mean value for $T$. urartu accessions

c Minimum value among T. urartu accessions

${ }^{d}$ Maximum value among $T$. urartu accessions

e Standard deviation of each set of phenotypic data

${ }^{f}$ Broad sense heritability

The correlation coefficient $(r)$ analysis revealed that several traits were correlated (Additional file 1: Table S5). The highest positive correlation was detected between TGW and GW ( $r$ ranging from 0.68 to 0.81 in different environments, significant at $P<0.01$ ), followed by TGW versus GL $(0.60-0.69, P<0.01)$, indicating that grain weight was largely influenced by grain size in $T$. urartu. In addition, significant positive correlations of HD with PH, SPL and SPLN were observed in all environments, suggesting that late-heading varieties were prone to have a high statue and large spike with many spikelets. On the other hand, HD was also negatively correlated with GL and GLW, demonstrating that a $T$. urartu accession with late heading date almost followed with small grain length and low grain length/width ratio. Notably, TA had a significant positive correlation with $\mathrm{PH}$ and SPLN, which reflected the tendency for prostrate type to have a high plant and a large number of spikelets.

\section{Genetic diversity revealed by SSR markers}

To evaluate the genetic diversity of the $T$. urartu population, 62 SSR primers (loci) distributed on seven chromosomes (Table 2) were selected to perform the nested-PCR amplifications and detected with fluorescent dye labeling system. In $238 \mathrm{~T}$. urartu accessions, a total of 1201 alleles ranging from 4 (Xbarc138) to 42 (Xgwm136) were amplified, with an average of 19.37 alleles per locus (Ao). 881 rare alleles (73.36\%) were detected with the frequency lower than $5 \%$, but none was fixed with the frequency more than $90 \%$, resulting in an average expected allele (Ae) of 7.29. This suggested that the higher genetic variations of alleles were present in T. urartu accessions. Consequently, the major allele frequencies varied from 0.13 (Xcfd15) to 0.86 (Xbarc206), with the overall mean of 0.32 .

We observed 18 heterozygous loci for the SSR markers assayed particularly, with the observed heterozygosity
( $\mathrm{Ho})$ and expected heterozygosity $(\mathrm{He})$ ranged between 0.04-0.72 and 0.24-0.85, respectively. As a result, a total of 1357 genotypes were deduced with an average of 21.89 per SSR marker. According to the polymorphic information content (PIC), 53 SSR loci (85.48\%) were highly informative (PIC $>0.5)$, eight $(12.90 \%)$ were reasonably informative $(0.5>\mathrm{PIC}>0.25)$ and only one (1.61\%) was slightly informative (PIC $<0.25)$. Calculation of the Nei's gene diversity (GD) for 62 loci demonstrated that $X c f a 2134$ preserved the highest GD $(\mathrm{GD}=0.94)$ and Xbarc206 did the lowest $(\mathrm{GD}=0.25)$, with the mean value of 0.80 . Hardy-Weinberg equilibrium testing of these markers indicated that $T$. urartu population is not mating randomly, probably owing to the self-pollination in diploid wheat (Additional file 1: Table S6).

The panel of analyzed T. urartu accessions possessed high polymorphic information, covering most original areas. In order to explore and compare the variability inherent in genetic diversity, variability parameters were calculated in eight sample subsets (Table 3). The number of alleles amplified in the Mesopotamia-Transcaucasia group was higher than that in the Eastern Mediterranean coastal group (16.38 versus 11.02, $P<0.01$ ), resulting in a general decrease in GD from 0.76 to 0.64 . Likewise, the Shannon's information indices (I) were counted as 1.97 versus 1.48 (Table 3). Beyond that, the Mesopotamia-Transcaucasia group preserved more rare alleles (frequency < 5\%) (498) than the Eastern Mediterranean coastal group (377). Our data demonstrated that the Mesopotamia-Transcaucasia group had much higher genetic diversity, and these regions might be the diversity center of $T$. urartu.

With respect to the geographic regions analyzed separately, the subpopulation of accessions collected from Turkey exhibited the highest diversity, followed by that from Northern Syria, Southwestern Syria, Lebanon, Iran, Jordan, Armenia and Iraq, due to their differences in number of alleles and genetic diversity (Table 3). GD in each population showed a similar trend ranging from 
Table 2 Diversity parameters revealed by SSR markers in 238 T. urartu accessions

\begin{tabular}{|c|c|c|c|c|c|c|c|c|c|c|c|c|}
\hline Loci & Chromosome & Position $(\mathrm{cM})^{a}$ & Repeat pattern & Size range (bp) & $\mathrm{Ao}^{\mathrm{b}}$ & $A e^{c}$ & $\mathrm{Gn}^{\mathrm{d}}$ & $\mathrm{MAF}^{\mathrm{e}}$ & $\mathrm{PIC}^{f}$ & $\mathrm{Ho}^{\mathrm{g}}$ & $\mathrm{He}^{\mathrm{h}}$ & $\mathrm{GD}^{\mathrm{i}}$ \\
\hline Xgwm136 & $1 \mathrm{~A}$ & 14 & $(C T) n$ & $224-308$ & 42 & 11.43 & 51 & 0.51 & 0.91 & 0.21 & 0.79 & 0.93 \\
\hline Xcfd15 & $1 \mathrm{~A}$ & 23 & $(\mathrm{CT}) \mathrm{n}(\mathrm{TGTA}) \mathrm{n}$ & $166-226$ & 26 & 14.85 & 28 & 0.13 & 0.93 & 0.07 & 0.76 & 0.91 \\
\hline Xbarc148 & $1 \mathrm{~A}$ & 43 & $(\mathrm{CT}) \mathrm{n}$ & 197-209 & 8 & 2.08 & 8 & 0.65 & 0.45 & 0 & 0.32 & 0.51 \\
\hline Xgwm357 & $1 \mathrm{~A}$ & 51 & $(G A) n$ & $122-158$ & 17 & 9.73 & 19 & 0.15 & 0.89 & 0 & 0.62 & 0.80 \\
\hline Xgwm164 & $1 \mathrm{~A}$ & 57 & $(C T) n$ & 118-148 & 15 & 5.87 & 16 & 0.28 & 0.81 & 0 & 0.62 & 0.83 \\
\hline Xcfa2129 & $1 \mathrm{~A}$ & 83 & $(G A) n$ & 154-206 & 25 & 9.05 & 25 & 0.23 & 0.91 & 0 & 0.77 & 0.89 \\
\hline Xcfa2219 & $1 \mathrm{~A}$ & 126 & $(\mathrm{GT}) \mathrm{n}$ & $214-250$ & 18 & 7.77 & 22 & 0.19 & 0.88 & 0.23 & 0.68 & 0.87 \\
\hline Xbarc17 & $1 \mathrm{~A}$ & 136 & $(T A A) n$ & $268-325$ & 19 & 5.72 & 19 & 0.32 & 0.86 & 0 & 0.50 & 0.83 \\
\hline Xgwm210.1 & $2 \mathrm{~A}$ & 4 & $(G A) n$ & $183-187$ & 5 & 1.70 & 5 & 0.73 & 0.35 & 0 & 0.39 & 0.41 \\
\hline Xgwm614 & $2 \mathrm{~A}$ & 10 & $(G A) n$ & 120-192 & 36 & 13.25 & 36 & 0.30 & 0.87 & 0 & 0.70 & 0.88 \\
\hline Xgwm328 & $2 \mathrm{~A}$ & 43 & $(\mathrm{GT}) \mathrm{n}$ & 199-212 & 15 & 8.05 & 26 & 0.28 & 0.87 & 0.36 & 0.72 & 0.88 \\
\hline Xgwm249.1 & $2 \mathrm{~A}$ & 59 & $(G A) n(G G A) n$ & 199-238 & 24 & 6.56 & 24 & 0.24 & 0.83 & 0 & 0.56 & 0.85 \\
\hline Xcfa2043 & $2 \mathrm{~A}$ & 71 & $(G A) n$ & $197-233$ & 21 & 6.86 & 21 & 0.24 & 0.83 & 0 & 0.73 & 0.85 \\
\hline Xcfa2058 & $2 \mathrm{~A}$ & 76 & $(\mathrm{TC}) \mathrm{n}$ & $252-290$ & 24 & 10.34 & 24 & 0.21 & 0.84 & 0 & 0.73 & 0.90 \\
\hline Xcfa2121 & $2 \mathrm{~A}$ & 82 & $(C A) n$ & $146-184$ & 22 & 14.98 & 42 & 0.17 & 0.90 & 0.49 & 0.79 & 0.93 \\
\hline Xgwm265 & $2 \mathrm{~A}$ & 100 & $(G T) n$ & 185-195 & 10 & 3.21 & 10 & 0.42 & 0.94 & 0 & 0.52 & 0.68 \\
\hline Xgwm382.1 & $2 \mathrm{~A}$ & 117 & $(G A) n$ & 110-170 & 30 & 14.41 & 30 & 0.16 & 0.63 & 0 & 0.76 & 0.93 \\
\hline Xcfa2086 & $2 \mathrm{~A}$ & 133 & $(C A) n$ & $217-284$ & 32 & 11.37 & 32 & 0.22 & 0.93 & 0 & 0.75 & 0.91 \\
\hline Xbarc57 & $3 \mathrm{~A}$ & 0 & $(T T A) n$ & $205-265$ & 22 & 8.25 & 22 & 0.19 & 0.91 & 0 & 0.73 & 0.88 \\
\hline Xbarc12 & $3 \mathrm{~A}$ & 25 & $(T A A) n$ & $167-227$ & 20 & 9.08 & 20 & 0.16 & 0.87 & 0 & 0.72 & 0.89 \\
\hline Xgwm369 & $3 \mathrm{~A}$ & 36 & $(\mathrm{CT}) \mathrm{nTT}(\mathrm{CT}) \mathrm{n}$ & 170-204 & 20 & 10.05 & 20 & 0.23 & 0.88 & 0 & 0.67 & 0.90 \\
\hline Xcfa2076 & $3 \mathrm{~A}$ & 61 & $(\mathrm{TG}) \mathrm{n}$ & $184-218$ & 14 & 4.02 & 14 & 0.42 & 0.89 & 0 & 0.55 & 0.75 \\
\hline Xgwm674 & $3 \mathrm{~A}$ & 80 & $(C T) n C C C(G T) n$ & $168-178$ & 7 & 1.92 & 7 & 0.66 & 0.42 & 0 & 0.24 & 0.47 \\
\hline Xcfa2134 & $3 \mathrm{~A}$ & 101 & $(\mathrm{TC}) \mathrm{n}$ & $207-283$ & 38 & 14.71 & 38 & 0.19 & 0.38 & 0 & 0.78 & 0.94 \\
\hline Xgwm480 & $3 \mathrm{~A}$ & 105 & $(C T) n(C A) n$ & 176-194 & 12 & 3.71 & 12 & 0.42 & 0.93 & 0 & 0.46 & 0.73 \\
\hline Xgwm247 & $3 \mathrm{~A}$ & 117 & $(G A) n$ & $202-214$ & 27 & 6.32 & 27 & 0.29 & 0.69 & 0 & 0.74 & 0.84 \\
\hline Xcfa2193 & $3 \mathrm{~A}$ & 171 & $(G T) n$ & $198-246$ & 24 & 6.31 & 24 & 0.30 & 0.83 & 0 & 0.56 & 0.84 \\
\hline Xbarc206 & $4 \mathrm{~A}$ & 0 & $(\mathrm{CT}) \mathrm{n}$ & $234-252$ & 9 & 1.37 & 12 & 0.86 & 0.29 & 0.04 & 0.24 & 0.25 \\
\hline Xgwm192.1 & $4 \mathrm{~A}$ & 29 & $(\mathrm{CT}) \mathrm{n}$ & $151-169$ & 9 & 2.89 & 9 & 0.49 & 0.24 & 0 & 0.34 & 0.65 \\
\hline Xbarc138 & $4 \mathrm{~A}$ & 39 & $(C T) n$ & 192-196 & 4 & 2.03 & 4 & 0.56 & 0.48 & 0 & 0.27 & 0.36 \\
\hline Xgwm397 & $4 \mathrm{~A}$ & 69 & $(\mathrm{CT}) \mathrm{n}$ & $195-235$ & 30 & 14.63 & 38 & 0.17 & 0.43 & 0.25 & 0.76 & 0.93 \\
\hline Xgwm269.2 & $4 \mathrm{~A}$ & 76 & $(C A) n$ & $113-197$ & 24 & 10.68 & 24 & 0.19 & 0.93 & 0 & 0.63 & 0.91 \\
\hline Xcfd88 & $4 \mathrm{~A}$ & 108 & $(C C G) n$ & 179-182 & 7 & 1.94 & 7 & 0.61 & 0.90 & 0 & 0.36 & 0.49 \\
\hline Xbarc70 & $4 \mathrm{~A}$ & 187 & (TATCTA)n(TCTA)n & $202-274$ & 21 & 8.85 & 21 & 0.43 & 0.38 & 0 & 0.41 & 0.74 \\
\hline Xbarc180 & $5 \mathrm{~A}$ & 12 & $(\mathrm{ATT}) \mathrm{n}$ & $184-226$ & 17 & 8.93 & 17 & 0.19 & 0.71 & 0 & 0.74 & 0.89 \\
\hline Xbarcl17 & $5 \mathrm{~A}$ & 18 & $(C A) n$ & $235-248$ & 8 & 2.65 & 11 & 0.50 & 0.88 & 0.04 & 0.44 & 0.62 \\
\hline Xgwm293 & $5 \mathrm{~A}$ & 27 & $(C A) n$ & $178-205$ & 17 & 3.73 & 17 & 0.45 & 0.68 & 0 & 0.57 & 0.84 \\
\hline Xbarc1 & $5 \mathrm{~A}$ & 30 & $(T A A) n$ & $255-297$ & 14 & 2.19 & 14 & 0.38 & 0.61 & 0 & 0.46 & 0.76 \\
\hline Xbarc165 & $5 \mathrm{~A}$ & 35 & $(A T T) n$ & $207-236$ & 19 & 7.94 & 28 & 0.24 & 0.54 & 0.69 & 0.85 & 0.87 \\
\hline Xbarc141 & $5 \mathrm{~A}$ & 39 & $(G A) n$ & 264-290 & 13 & 4.84 & 13 & 0.30 & 0.86 & 0 & 0.60 & 0.79 \\
\hline Xbarc330 & $5 \mathrm{~A}$ & 48 & $(\mathrm{CT}) \mathrm{n}$ & $108-160$ & 28 & 11.45 & 28 & 0.17 & 0.77 & 0 & 0.75 & 0.91 \\
\hline Xbarc151 & $5 \mathrm{~A}$ & 54 & $(C T) n$ & $202-224$ & 12 & 4.65 & 12 & 0.38 & 0.76 & 0 & 0.61 & 0.78 \\
\hline Xgwm639 & $5 \mathrm{~A}$ & 64 & $(G A) n$ & $146-169$ & 26 & 8.34 & 26 & 0.19 & 0.87 & 0 & 0.70 & 0.88 \\
\hline Xgwm179 & $5 \mathrm{~A}$ & 96 & (GT)n & 194-208 & 8 & 3.55 & 8 & 0.33 & 0.67 & 0 & 0.23 & 0.72 \\
\hline
\end{tabular}


Table 2 Diversity parameters revealed by SSR markers in 238 T. urartu accessions (Continued)

\begin{tabular}{|c|c|c|c|c|c|c|c|c|c|c|c|c|}
\hline Xgwm410.1 & $5 \mathrm{~A}$ & 109 & $(C A) n$ & $288-345$ & 37 & 11.58 & 54 & 0.25 & 0.91 & 0.72 & 0.78 & 0.91 \\
\hline Xgwm334 & $6 \mathrm{~A}$ & 28 & $(G A) n$ & $127-153$ & 26 & 8.85 & 42 & 0.23 & 0.88 & 0.28 & 0.74 & 0.89 \\
\hline Xbarc3 & $6 \mathrm{~A}$ & 66 & $(\mathrm{CCT}) \mathrm{n}$ & $206-256$ & 30 & 9.67 & 30 & 0.33 & 0.84 & 0 & 0.63 & 0.85 \\
\hline Xcfd80 & $6 \mathrm{~A}$ & 84 & $(G A) n$ & $165-183$ & 11 & 4.04 & 11 & 0.40 & 0.72 & 0 & 0.53 & 0.75 \\
\hline Xgwm132 & $6 \mathrm{~A}$ & 111 & $(G A) n(G A A) n$ & $112-146$ & 20 & 7.01 & 33 & 0.33 & 0.85 & 0.69 & 0.81 & 0.86 \\
\hline Xgwm570 & $6 \mathrm{~A}$ & 118 & $(\mathrm{CT}) \mathrm{n}(\mathrm{GT}) \mathrm{n}$ & 130-152 & 11 & 3.86 & 11 & 0.38 & 0.70 & 0 & 0.49 & 0.74 \\
\hline Xbarc104 & $6 \mathrm{~A}$ & 125 & $(T A A) n$ & $174-213$ & 13 & 3.11 & 13 & 0.40 & 0.63 & 0 & 0.54 & 0.78 \\
\hline Xgwm427 & $6 \mathrm{~A}$ & 137 & $(C A) n$ & $154-228$ & 31 & 12.14 & 31 & 0.17 & 0.91 & 0 & 0.72 & 0.92 \\
\hline Xgwm617 & $6 \mathrm{~A}$ & 140 & $(G A) n$ & $106-166$ & 11 & 5.28 & 11 & 0.28 & 0.78 & 0 & 0.42 & 0.75 \\
\hline Xgwm471 & $7 \mathrm{~A}$ & 20 & $(C A) n$ & $120-186$ & 32 & 9.95 & 32 & 0.27 & 0.89 & 0 & 0.76 & 0.90 \\
\hline Xcfd242 & $7 \mathrm{~A}$ & 39 & $(G T T) n(A G C) n$ & 219-237 & 8 & 3.47 & 12 & 0.39 & 0.66 & 0.30 & 0.58 & 0.75 \\
\hline Xbarc127 & $7 \mathrm{~A}$ & 47 & $(\mathrm{CT}) \mathrm{n}$ & $196-264$ & 22 & 9.18 & 37 & 0.19 & 0.88 & 0.21 & 0.73 & 0.89 \\
\hline Xbarc154 & $7 \mathrm{~A}$ & 49 & $(\mathrm{CT}) \mathrm{n}$ & $237-285$ & 22 & 5.60 & 26 & 0.29 & 0.80 & 0.07 & 0.61 & 0.82 \\
\hline Xbarc174 & $7 \mathrm{~A}$ & 71 & (ATT)n & $170-227$ & 21 & 8.85 & 21 & 0.21 & 0.88 & 0 & 0.55 & 0.89 \\
\hline Xgwm276 & $7 \mathrm{~A}$ & 84 & $(\mathrm{CT}) \mathrm{n}$ & $97-129$ & 16 & 4.93 & 20 & 0.37 & 0.77 & 0.06 & 0.61 & 0.80 \\
\hline$x c f d 20$ & $7 \mathrm{~A}$ & 103 & $(G G A A) n(C T A C) n$ & $288-459$ & 11 & 4.17 & 14 & 0.35 & 0.73 & 0.13 & 0.57 & 0.76 \\
\hline Xgwm63 & $7 \mathrm{~A}$ & 106 & $(C A) n(T A) n$ & 157-183 & 16 & 6.61 & 24 & 0.30 & 0.83 & 0.18 & 0.69 & 0.85 \\
\hline Xcfa2040 & $7 \mathrm{~A}$ & 124 & $(C A) n$ & $293-341$ & 24 & 11.45 & 24 & 0.17 & 0.91 & 0 & 0.73 & 0.91 \\
\hline Mean & & & & & 19.37 & 7.29 & 21.89 & 0.32 & 0.76 & 0.08 & 0.61 & 0.80 \\
\hline
\end{tabular}

${ }^{a}$ Indicated map positions in bread wheat according to Song et al. [48]

${ }^{\mathrm{b}}$ Number of observed alleles

${ }^{\mathrm{C}}$ Expected number of alleles

${ }^{d}$ Number of genotype at each locus

${ }^{\mathrm{e}}$ Frequency of major allele

f Polymorphism information content

${ }^{g}$ Observed heterozygosity

${ }^{\mathrm{h}}$ Expected heterozygosity

'Nei's Gene diversity

Table 3 Genetic diversity for different T. urartu subsets based on 62 SSR markers

\begin{tabular}{|c|c|c|c|c|c|c|}
\hline Subset of accessions & Sample Size & $\mathrm{AO}^{\mathrm{a}}$ & $A e^{b}$ & $\mathrm{PIC}^{\mathrm{c}}$ & $G D^{d}$ & $\mathrm{I}^{\mathrm{e}}$ \\
\hline All samples & 238 & 19.37 & 7.29 & 0.76 & 0.80 & 2.04 \\
\hline Eastern Mediterranean coast & 112 & 11.02 & 3.91 & 0.61 & 0.64 & 1.48 \\
\hline Lebanon & 84 & 6.41 & 2.83 & 0.49 & 0.52 & 1.18 \\
\hline Southwestern Syria & 17 & 7.50 & 4.89 & 0.66 & 0.69 & 1.59 \\
\hline Jordan & 11 & 3.27 & 2.25 & 0.40 & 0.45 & 0.83 \\
\hline Mesopotamia-Transcaucasia & 126 & 16.38 & 6.71 & 0.74 & 0.76 & 1.97 \\
\hline Turkey & 81 & 11.71 & 5.18 & 0.72 & 0.75 & 1.73 \\
\hline Northern Syria & 19 & 8.73 & 5.07 & 0.69 & 0.71 & 1.71 \\
\hline Iraq & 3 & 2.69 & 2.55 & 0.45 & 0.52 & 1.08 \\
\hline Iran & 11 & 5.53 & 4.28 & 0.66 & 0.69 & 1.41 \\
\hline Armenia & 12 & 3.08 & 1.77 & 0.33 & 0.37 & 0.68 \\
\hline
\end{tabular}

${ }^{a}$ Number of observed alleles

${ }^{b}$ Expected number of alleles

c Polymorphism information content

${ }^{\mathrm{d}}$ Nei's Gene diversity

e Shannon's information indices 
0.75 (Turkey) to 0.37 (Armenia). The maximum and the minimum Shannon's information indices (I) were observed as well in Turkish (1.73) and Armenian (0.68) accessions, respectively.

\section{Genetic diversity revealed by HMW-GSs}

The pattern of HMW-GSs from most of the T. urartu accessions is formed by two distinct electrophoretic moving zones, including one major $1 \mathrm{Ax}$ subunit zone with slower mobility and one major 1 Ay subunit zone with faster mobility (Fig. 2). Among the 238 T. urartu accessions, the 1Ay subunit was not expressed in 69 accessions (28.99\%), and only one $(0.42 \%)$ was found silenced for the $1 \mathrm{Ax}$ subunit. All the 1Ax subunits in T. urartu showed faster electrophoretic mobility than the subunit $1 \mathrm{Ax} 1$ detected in bread wheat Xiaoyan $54(\mathrm{XY})$, and four $1 \mathrm{Ax}$ subunits in 46 accessions displayed slower electrophoretic mobility than the $1 \mathrm{Ax} 2$ " present in bread wheat Cheyenne (CNN) (Fig. 2). In most $T$. urartu accessions, the electrophoretic mobility of the 1 Ay subunits was faster than the 1 Dy 10 subunit of Cheyenne, except for one Armenian and two Turkish accessions (U17).

A total of eleven $1 \mathrm{Ax}$ and eight $1 \mathrm{Ay}$ subunits were detected, resulting in 18 HMW-GS genotypes (U1-U18) (Table 4). U1, U6 and U10 appeared exclusively in Turkish accessions, U14, U15 and U16 only in Lebanese accessions, U5 merely in southwestern Syria, and U12 and U18 were solely present in northern Syria. Concerning the frequencies of these HMW-GS genotypes, U7 was the most abundant (65 accessions, 27.31\%), followed by U8 (42 accessions, 17.65\%), U2 (35 accessions, 14.71\%) and U14 (21 accessions, $8.82 \%$ ). The remaining 14 patterns totally accounted for $31.51 \%$ of accessions, of which U1, U6 and U18 were each present in only one accession. When considering the HMW-GS locus as a co-dominant marker, its PIC and GD were 0.86 and 0.88 , respectively, which were comparable with these of the SSR markers.

\section{Genetic relationships among the accessions}

The information about genetic variation determined from SSR data combining with the SDS-PAGE analysis of HMW-GS was employed to estimate similarity matrix value. Based on Jaccard's coefficient, an UPGMA dendrogram was constructed to reveal the genetic relationships (Fig. 3). The phylogenetic tree clearly assigned the $238 \mathrm{~T}$. urartu accessions into two clusters: Cluster I mainly distributed in the east of Mediterranean coastal regions, including Lebanon, Jordan and southwestern Syria, and Cluster II tended to occur in the Mesopotamia and Transcaucasia regions, including Turkey, Iraq, Iran, Armenia and northern Syria. The genetic distance in the dendrogram revealed that Cluster II exhibited more diversity than Cluster I, which was consistent with its extensive geographic distribution. In Cluster I, Lebanese accessions (84) gathered tightly and were further distinguished from the other accessions, thus this cluster split into two major subclasses. Cluster II was also divided into two subclasses, one of which contained all the Iraqi and Iranian accessions (14), most of Turkish and northern Syrian accessions (84), and one Armenian accession, whereas the other one contained eight Turkish accessions, six northern Syrian accessions and eleven Armenian accessions. Typically, the sequenced accession, PI428198 (G1812) [5] grouped with most Turkish materials at the first subclass of Cluster II. The Mantel test revealed a high and significant cophenetic correlation $(r=0.92, P<0.001)$, indicating a good fit between the dendrogram and its original similarity matrix. The range of similarity coefficients (0.03-0.97) showed abundant genetic variation in this collection, which is supported by the high means observed for the number of alleles per locus and the PIC values.

Principal coordinates analysis ( $\mathrm{PCoA})$ was also performed in order to assess the individual differences (Fig. 4). The first two axes accounted for 42.25 and $17.28 \%$ of the genetic variation, respectively, and occupied $59.53 \%$ in total. The first coordinate clearly discriminated Eastern Mediterranean coastal accessions from Mesopotamia-Transcaucasia accessions, while the second coordinate separated the two large clusters gradually into small groups due to the latitude variation. The PCoA data confirmed the UPGMA analysis.

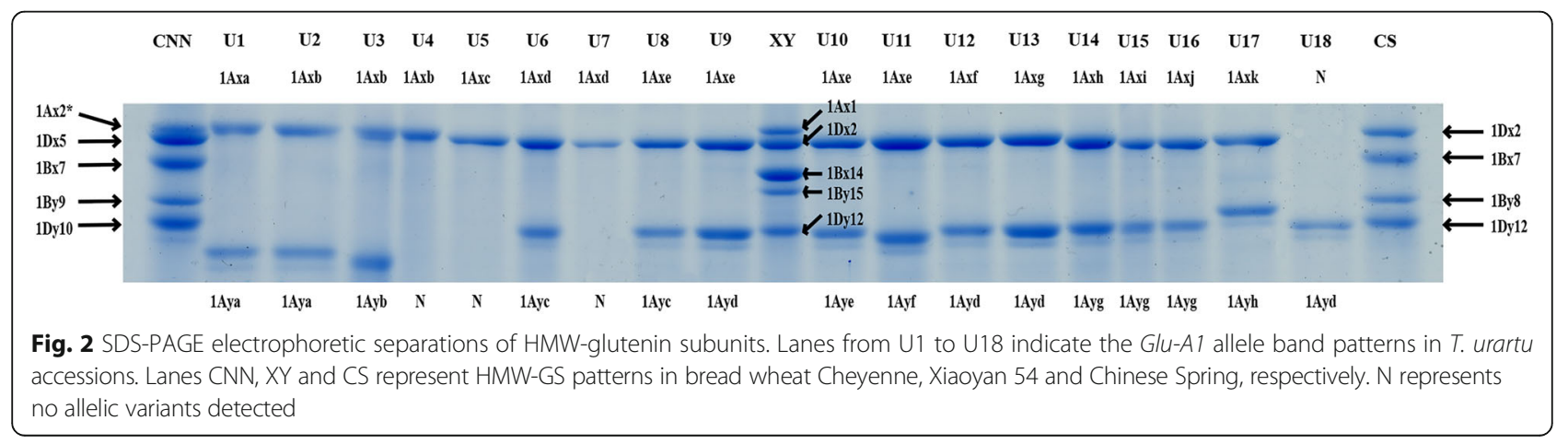


Table 4 Summary of the HMW-GS patterns analyzed by SDS-PAGE

\begin{tabular}{|c|c|c|c|c|c|c|c|c|c|c|c|c|}
\hline \multirow[t]{2}{*}{ HMW pattern } & \multirow[t]{2}{*}{$1 \mathrm{Ax}$} & \multirow[t]{2}{*}{$1 \mathrm{Ay}$} & \multicolumn{8}{|c|}{ Original region } & \multirow[t]{2}{*}{ Accession Number } & \multirow{2}{*}{$\begin{array}{l}\text { Frequency } \\
\text { (\%) }\end{array}$} \\
\hline & & & Lebanon & Jordan & Southwestern Syria & Turkey & Northern Syria & Iraq & Iran & Armenia & & \\
\hline U1 & a & a & & & & 1 & & & & & 1 & 0.42 \\
\hline U2 & $b$ & a & & & 3 & 27 & 1 & 1 & 3 & & 35 & 14.71 \\
\hline U3 & $b$ & $b$ & & 7 & 1 & & & & & & 8 & 3.36 \\
\hline U4 & $b$ & $\mathrm{~N}^{\mathrm{a}}$ & & & & 1 & & & & 1 & 2 & 0.84 \\
\hline U5 & c & $\mathrm{N}^{\mathrm{a}}$ & & & 2 & & & & & & 2 & 0.84 \\
\hline U6 & $d$ & c & 1 & & & & & & & & 1 & 0.42 \\
\hline U7 & $d$ & $\mathrm{~N}^{\mathrm{a}}$ & 5 & 4 & 12 & 31 & 2 & & 1 & 10 & 65 & 27.31 \\
\hline U8 & e & c & 40 & & 1 & & & & 1 & & 42 & 17.65 \\
\hline U9 & e & $d$ & & & & 5 & 8 & 1 & 2 & & 16 & 6.72 \\
\hline U10 & e & e & & & & 5 & & & & & 5 & 2.10 \\
\hline U11 & e & $f$ & & & & 7 & 2 & 1 & 4 & & 14 & 5.88 \\
\hline U12 & f & $d$ & & & & & 3 & & & & 3 & 1.26 \\
\hline U13 & g & $d$ & & & & 1 & 1 & & & & 2 & 0.84 \\
\hline U14 & h & $g$ & 21 & & & & & & & & 21 & 8.82 \\
\hline U15 & i & g & 2 & & & & & & & & 2 & 0.84 \\
\hline U16 & j & $g$ & 15 & & & & & & & & 15 & 6.30 \\
\hline U17 & k & h & & & & 2 & & & & 1 & 3 & 1.26 \\
\hline U18 & $\mathrm{N}^{\mathrm{a}}$ & $\mathrm{d}$ & & & & & 1 & & & & 1 & 0.42 \\
\hline
\end{tabular}

${ }^{a}$ Not detected allelic variants

\section{Population structure}

In order to understand the population stratification of $T$. urartu, the model-based Bayesian cluster analysis was tested using the software program STRUCTURE (Fig. 5). The data was analyzed by successively increasing the number of subpopulations $(K)$ from two to fifteen, with five independent runs for each $K$ value. The CLUMPP alignment of independent solutions showed the high posterior probability in assignment of accessions among runs. At $K=2$, we detected a division between 112 eastern Mediterranean coastal accessions (Cluster I) and 126 Mesopotamia-Transcaucasia accessions (Cluster II). At $K=3$, Cluster II split into 61 Turkish accessions and the remainders, while 58 Lebanese accessions were segregated from the rest of Cluster I when $K=4$. With increasing $K$, minor subpopulations from different geographic regions such as Jordan, Iran, Iraq and Armenia could be separated gradually. The optimum number of subpopulations $(K)$ was identified based on $\ln \mathrm{P}(\mathrm{D})$ value and the delta $K(\Delta K)$ method suggested $K=2$ as the best fitting one in our study (Additional file 2: Fig. S1). This structure-based data was mainly consistent with the genetic relationships of the traditional clusters.

Based on AMOVA analysis, most genetic variation was detected among individuals (60.04\%), followed by variation among geographic regions (18.93\%), variation within individuals (12.87\%) and variation among the large two Clusters (8.16\%). The overall Fst among the Clusters and geographic regions were 0.1790 and 0.2506 , respectively $(P<0.05)$. The pairwise $F s t$ value, interpreted as standardized population distances between two populations, ranged from 0.0658 (between Turkish and northern Syrian populations) to 0.4419 (between Jordanian and Armenian populations). The Nei's genetic distance data consisted with the Fst estimates, in which Turkish population showed the smallest genetic distance with northern Syrian population (0.0289), whereas the greatest genetic distance was observed between Jordanian and Armenian populations (0.7947) (Table 5).

\section{Linkage disequilibrium and marker-trait association analysis}

The SSR and HWM-GS data were subjected to evaluate the linkage disequilibrium (LD) on a whole genome level. Across all the 63 loci, 1953 locus pairs were detected in the entire $T$. urartu collection, with 257 possible linked (in the same linkage groups) and 1696 unlinked locus pairs (from different linkage groups), respectively. Among these linked locus pairs, the pairwise $r^{2}$ values varied from 0.00 to 0.25 with a median of 0.04 , and only nine $(3.50 \%)$ marker pairs were at significant LD level $\left(r^{2}>0.1\right.$ and $\left.P<0.001\right)$, which suggested seldom LD among the analyzed loci.

The association analysis between markers and phenotypic data was carried out using GLM and MLM models 


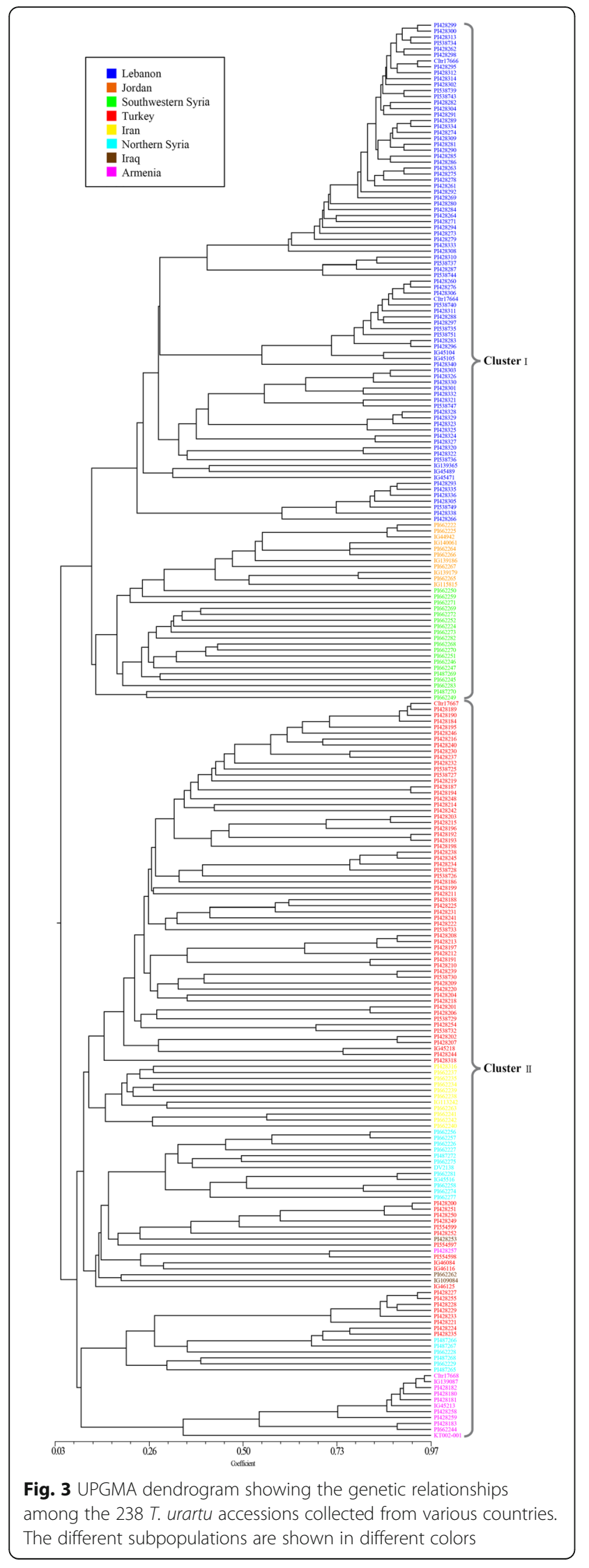

in the software TASSEL. Among the $63 \times 9$ marker-trait comparisons, 67 significant associations $(11.82 \%)$ were identified using GLM approach with Q-matrix. However, the MLM analysis reduced to 10 significant associations $(1.76 \%)$ once considering K-matrix as co-variate. The Qmatrix $(K=2)$ inferred from STRUCTURE defined the ancestry coefficient of individuals in the population and the K-matrix was subjected to correct for their genetic relatedness. Besides, the averages of the phenotypic variations calculated by the two models for association mapping were $15.89 \%(\mathrm{Q})$ and $22.74 \%(\mathrm{Q}+\mathrm{K})$, indicating that the MLM could explain more genetic variation than GLM. Henceforth, our attention will focus on associations incorporating both Q-matrix and K-matrix since they were more conservative and accurate.

Considering the MLM statistics, significant markertrait associations for six traits were identified with six SSRs and protein marker HMW-GSs (HD: Xcfa2193-3A; PH: Xgwm328-2A; SPL: Xgwm328-2A and Xgwm63-7A; SPLN: Xgwm328-2A, Xgwm63-7A and Xbarc138-4A; TA: HMW-GS; GL: $X c f a 2219-1 A$ and $X g w m 293-5 A$ ) in T. urartu accessions (Table 6). The Xcfa2193-3A on chromosome $3 \mathrm{~A}$ was highly associated with HD in four environments, explaining 9.39 to $15.74 \%$ of the phenotypic variation, while Xgwm328-2A on chromosome $2 \mathrm{~A}$ was closely associated with $\mathrm{PH}$ in all the six environments, accounting for 23.47 to $32.15 \%$ of the phenotypic variation. Xgwm328-2A was also simultaneously associated with SPL and SPLN in at least five environments, having the phenotypic variations of 32.43 to $37.90 \%$ and 28.42 to $38.77 \%$, respectively. This multiple marker-trait association might be attributed to the pleiotropic effects of the genetic locus or the consequential relationship among these associated traits. Xgwm63-7A was significantly associated with SPL and SPLN in five environments, with the phenotypic variations of 20.67 to $27.80 \%$ and 19.24 to $23.93 \%$, respectively, and Xbarc138-4A showed a stable association with SPLN in four environments, with the phenotypic variations of 14.43 to $18.18 \%$. In particular, the HMW-GSs, encoded by Glu-1 locus on the long arm of chromosome $1 \mathrm{~A}$, were associated with TA in three environments, and it explained phenotypic variations ranging from 28.18 to $34.46 \%$. As for grain traits, Xcfa2219-1A and Xgwm293-5A were associated with grain length (GL) in five environments, and could explain 15.99 to $20.33 \%$ and 23.55 to $28.23 \%$ of the phenotypic variation, respectively.

We further investigated the relationships between the genotype and haplotype with the phenotypic traits analyzed (Fig. 6). For HD, the 214-bp genotype of Xcfa2193$3 A$, which was observed in 10 Armenian accessions, exerted a positive effect on delaying the heading date, whereas the 202-bp genotype in 72 accessions was linked to medium heading date. Furthermore, the 200bp allele present at Xgwm328-2A locus in 11 accessions 


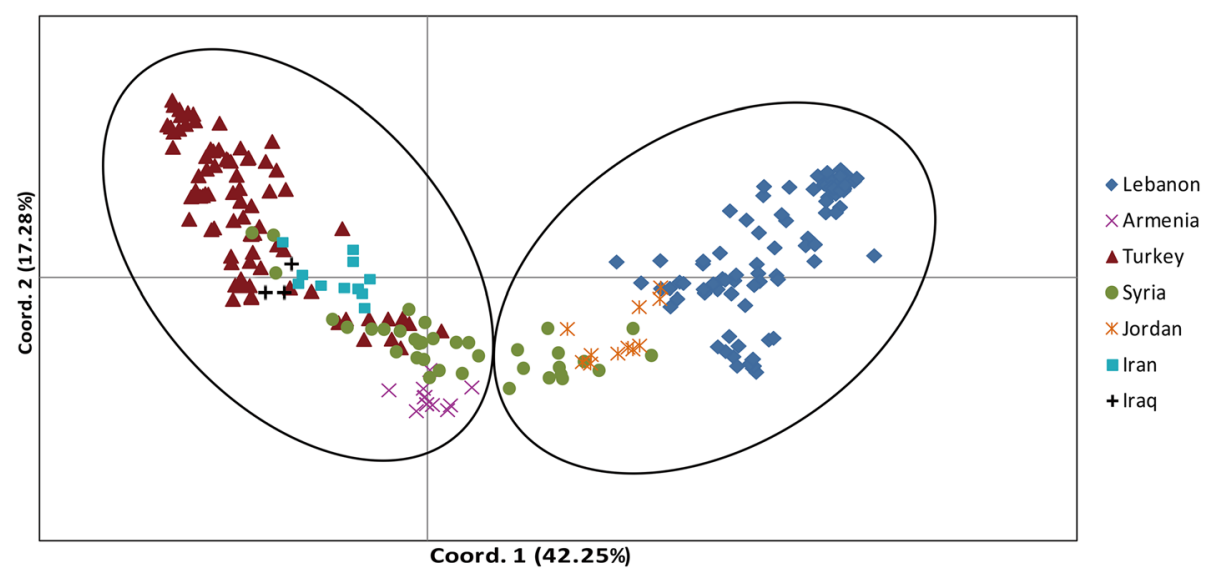

Fig. 4 Principal coordinates analysis of 238 T. urartu accessions. The first and second principal coordinates account for $42.25 \%$ and $17.28 \%$ of the total variation respectively. The different colors represent the accessions of different geographical origins

was strongly associated with high values of $\mathrm{PH}$, which also correlated with the increase of SPL and SPLN. In contrast, the 208-bp allele was preferentially shared by genotypes in 29 accessions with low PH, SPL and SPLN. Similarly, 55 accessions carrying the 170-bp allele at Xgwm63-7A produced remarkably longer SPL and more SPLN than accessions with other alleles, and the 196-bp allele at Xbarc138-4A could also bring more SPLN in 17 accessions than others. At Glu-1 locus, the HMW-GS encoded U7 pattern was associated with the erect plant architecture (65 accessions), whereas the U14 pattern with the prostrate type (21 accessions). Regarding GL, the significant associations were attributed to the 224-bp allele at Xcfa2219-1A and the 205-bp allele at Xgwm293$5 A$ being specific to genotypes with large kernel length.

\section{Discussion}

Nowadays, the genetic variability of wheat cultivars is decreasing as a consequence of the genetic erosion of cultivated hexaploid wheat. As a wild diploid progenitor of hexaploid wheat, $T$. urartu harbors rich allelic diversity for numerous important traits, including agronomic
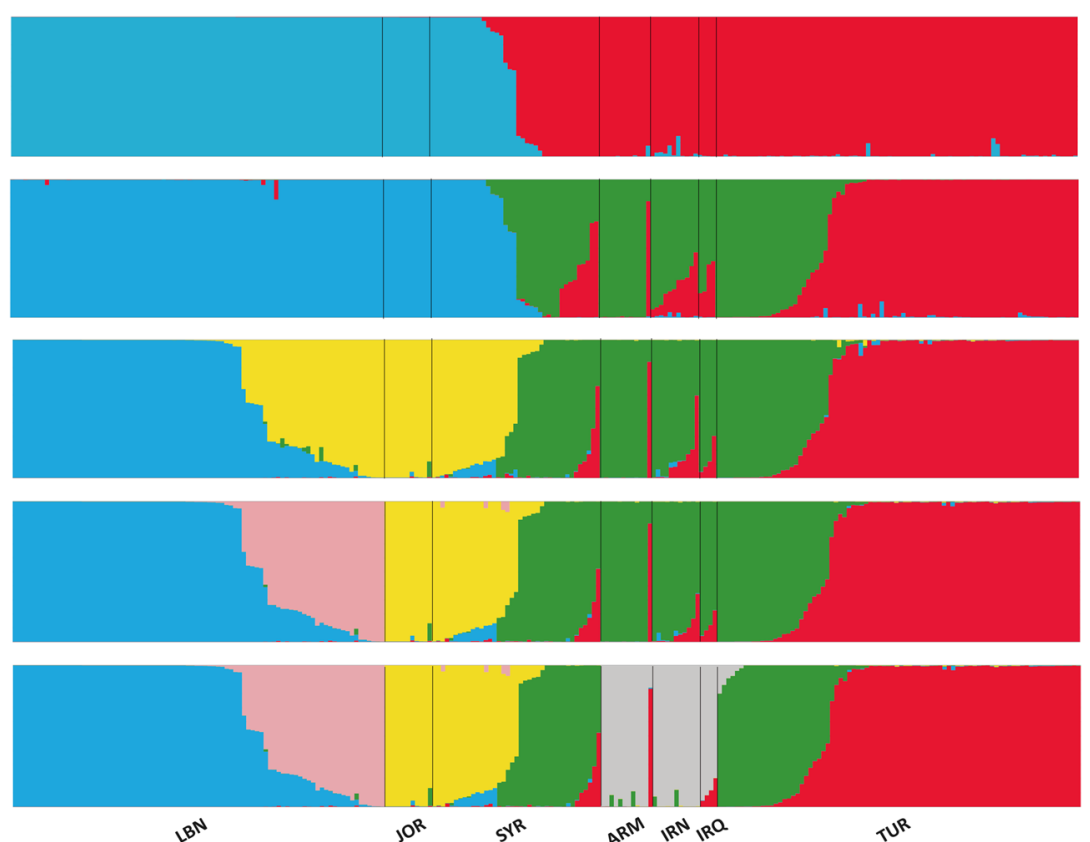

Fig. 5 Estimated population structure from 62 nuclear SSR loci based on Bayesian clustering approaches for $K=2$ to $K=6$ using STRUCTURE. Each accession is represented by a vertical line. The different subpopulations are separated by a black line and shown in different colors. The bottom row indicates the geographic region. LBN, Lebanon; JOR, Jordan; SYR, Syria; ARM, Armenia; IRN, Iran; IRQ, Iraq; TUR, Turkey 
Table 5 Pairwise estimates of Fst and Nei's genetic distance between populations from different regions

\begin{tabular}{lllllllll}
\hline Cluster & Lebanon & Jordan & Southwestern Syria & Turkey & Armenia & Iran & Iraq & Northern Syria \\
\hline Lebanon & & 0.3060 & 0.3283 & 0.4628 & 0.7244 & 0.4340 & 0.6343 & 0.5932 \\
Jordan & 0.2044 & & 0.0334 & 0.4419 & 0.7947 & 0.4399 & 0.6596 & 0.5129 \\
Southwestern Syria & 0.1590 & 0.1284 & & 0.2507 & 0.5222 & 0.1944 & 0.4769 & 0.2061 \\
Turkey & 0.1813 & 0.2022 & 0.1058 & & 0.4803 & 0.0312 & 0.1696 & 0.0289 \\
Armenia & 0.3290 & 0.4419 & 0.2361 & 0.2251 & & 0.3852 & 0.4790 & 0.4587 \\
Iran & 0.1876 & 0.2131 & 0.1043 & 0.0790 & 0.2180 & & 0.1731 & 0.0434 \\
Iraq & 0.2151 & 0.2343 & 0.1333 & 0.0985 & 0.2567 & 0.1081 & 0.0295 \\
Northern Syria & 0.1826 & 0.1968 & 0.0953 & 0.0658 & 0.2164 & 0.0788 & 0.0690
\end{tabular}

Nei's genetic distance estimates appear above the diagonal and pairwise Fst appears below the diagonal

characteristics, dough quality and biotic stress tolerance [9-11]. Thus, this wild species could be exploited in yield potential and quality improvement of bread wheat.

\section{Morphological and genetic diversity}

In recent years, SSRs markers have been proven to be an efficient tool for molecular and genetic studies in wheat [47-49]. Many SSRs covering the A genome of common wheat were employed in diploid wheat, due to their transferability among closely related species [50]. In this work, we observed a higher level of polymorphisms in $T$. urartu using SSR markers developed in common wheat. A total of 1201 alleles were identified from the 62 SSR loci in the 238 accessions, with an average of 19.37 alleles per locus, which is much higher than that observed in an earlier study (19.37 vs. 8.00) of $23 \mathrm{~T}$. urartu accessions using 25 SSRs [51]. In addition, low genetic variation of T. urartu has also been reported with RFLP and RAPD markers [12-14]. This is the first time that such a high level of genetic diversity was characterized in T. urartu using SSR markers, probably because of a relatively large number of accessions collected in a wider geographic region. Moreover, compared to other wheat species, T. urartu possesses higher level of genetic diversity than the A genome of tetraploid and hexaploid wheat $[52,53]$.

HMW-GSs are the major seed storage proteins that determine dough viscoelastic properties and breadmaking quality [54, 55], which could also represent useful markers for assessment of genetic variability in wild diploid wheat collections [56, 57]. In present study, a total of eleven $1 \mathrm{Ax}$ and eight $1 \mathrm{Ay}$ subunits were detected, resulting in $18 \mathrm{HMW}-\mathrm{GS}$ combinations in 238 accessions. Even though 1Ay subunit is totally inactive in common wheat [58], 71.01\% T. urartu accessions were found to express the 1 Ay subunit, which was consistent with previous reports [56, 59, 60]. The polymorphic information content (PIC) of our collections was 0.86 , and the GD value was 0.88 , which suggested that genetic variation revealed by HMW-GSs was comparable with that by SSR markers, probably because of the post-translational modification of protein markers.

The genetic diversity observed in this study is well reflected by the variation in multiple biological traits.

Table 6 Common loci and significant markers associated with agronomic and grain shape related traits

\begin{tabular}{|c|c|c|c|c|c|c|c|c|c|c|c|c|c|c|}
\hline \multirow[t]{3}{*}{ Trait } & \multirow[t]{3}{*}{ Loci } & \multirow[t]{3}{*}{ Chromosome } & \multicolumn{6}{|l|}{$P$ value $^{\mathrm{b}}$} & \multicolumn{6}{|c|}{$R^{2}(\%)^{c}$} \\
\hline & & & \multicolumn{3}{|l|}{$2014^{\mathrm{a}}$} & \multicolumn{3}{|l|}{2015} & \multicolumn{3}{|l|}{2014} & \multicolumn{3}{|l|}{2015} \\
\hline & & & $\overline{E 1}$ & E2 & E3 & E4 & E5 & E6 & E1 & E2 & E3 & E4 & E5 & E6 \\
\hline $\mathrm{HD}$ & Xcfa2193 & $3 \mathrm{~A}$ & $4.30 \times 10^{-4}$ & 0.0032 & - & $9.62 \times 10^{-4}$ & - & $1.71 \times 10^{-5}$ & 10.62 & 15.74 & - & 9.39 & - & 9.75 \\
\hline $\mathrm{PH}$ & Xgwm328 & $2 \mathrm{~A}$ & $1.45 \times 10^{-5}$ & $1.04 \times 10^{-6}$ & 0.0044 & $9.84 \times 10^{-5}$ & $2.07 \times 10^{-4}$ & $2.34 \times 10^{-6}$ & 30.54 & 28.21 & 25.81 & 23.47 & 27.23 & 32.15 \\
\hline \multirow[t]{2}{*}{ SPL } & Xgwm328 & $2 \mathrm{~A}$ & $8.67 \times 10^{-10}$ & $5.06 \times 10^{-8}$ & $5.35 \times 10^{-4}$ & $1.58 \times 10^{-10}$ & $6.85 \times 10^{-5}$ & $4.74 \times 10^{-6}$ & 35.10 & 37.90 & 32.43 & 36.60 & 35.32 & 35.44 \\
\hline & Xgwm63 & $7 \mathrm{~A}$ & $5.19 \times 10^{-5}$ & - & $6.57 \times 10^{-5}$ & $3.48 \times 10^{-4}$ & 0.0015 & $1.97 \times 10^{-4}$ & 26.92 & - & 20.67 & 27.80 & 25.11 & 21.59 \\
\hline \multirow[t]{3}{*}{ SPLN } & Xgwm328 & $2 \mathrm{~A}$ & 0.0024 & $9.95 \times 10^{-4}$ & $3.99 \times 10^{-4}$ & 0.0072 & $7.07 \times 10^{-4}$ & - & 34.19 & 38.77 & 33.97 & 28.42 & 35.45 & - \\
\hline & Xbarc138 & $4 \mathrm{~A}$ & - & $6.84 \times 10^{-4}$ & 0.0027 & $8.74 \times 10^{-4}$ & - & 0.0076 & - & 15.72 & 18.18 & 14.43 & - & 15.18 \\
\hline & Xgwm63 & $7 \mathrm{~A}$ & $1.24 \times 10^{-4}$ & - & $9.42 \times 10^{-5}$ & $2.82 \times 10^{-5}$ & 0.0039 & $5.53 \times 10^{-4}$ & 23.93 & - & 21.85 & 19.24 & 22.25 & 21.85 \\
\hline TA & HWM-GS & $1 \mathrm{~A}$ & - & $2.39 \times 10^{-4}$ & - & 0.0059 & $6.25 \times 10^{-4}$ & - & - & 34.46 & - & 28.18 & 31.09 & - \\
\hline \multirow[t]{2}{*}{ GL } & Xcfa2219 & $1 \mathrm{~A}$ & 0.0050 & $4.45 \times 10^{-6}$ & 0.0098 & $6.87 \times 10^{-5}$ & - & $9.89 \times 10^{-4}$ & 19.89 & 16.92 & 20.33 & 15.99 & - & 17.93 \\
\hline & Xgwm293 & $5 A$ & $2.29 \times 10^{-6}$ & 0.0081 & $3.22 \times 10^{-4}$ & $9.11 \times 10^{-6}$ & 0.0035 & - & 28.23 & 26.95 & 27.34 & 24.83 & 23.55 & - \\
\hline
\end{tabular}

Marker-trait association was performed with linear mixed-effects model (MLM) incorporating structure Q-matrix and kinship K-matrix in TASSEL 2.1

${ }^{\text {a }}$ Missing result is represented by ' - ' due to unavailable data

${ }^{\mathrm{b}}$ Marker-trait association is significant at $P<0.01$ with FDR correction at ac $=0.05$

${ }^{c} R^{2}$ is the percentage of phenotypic variation explained by the marker 


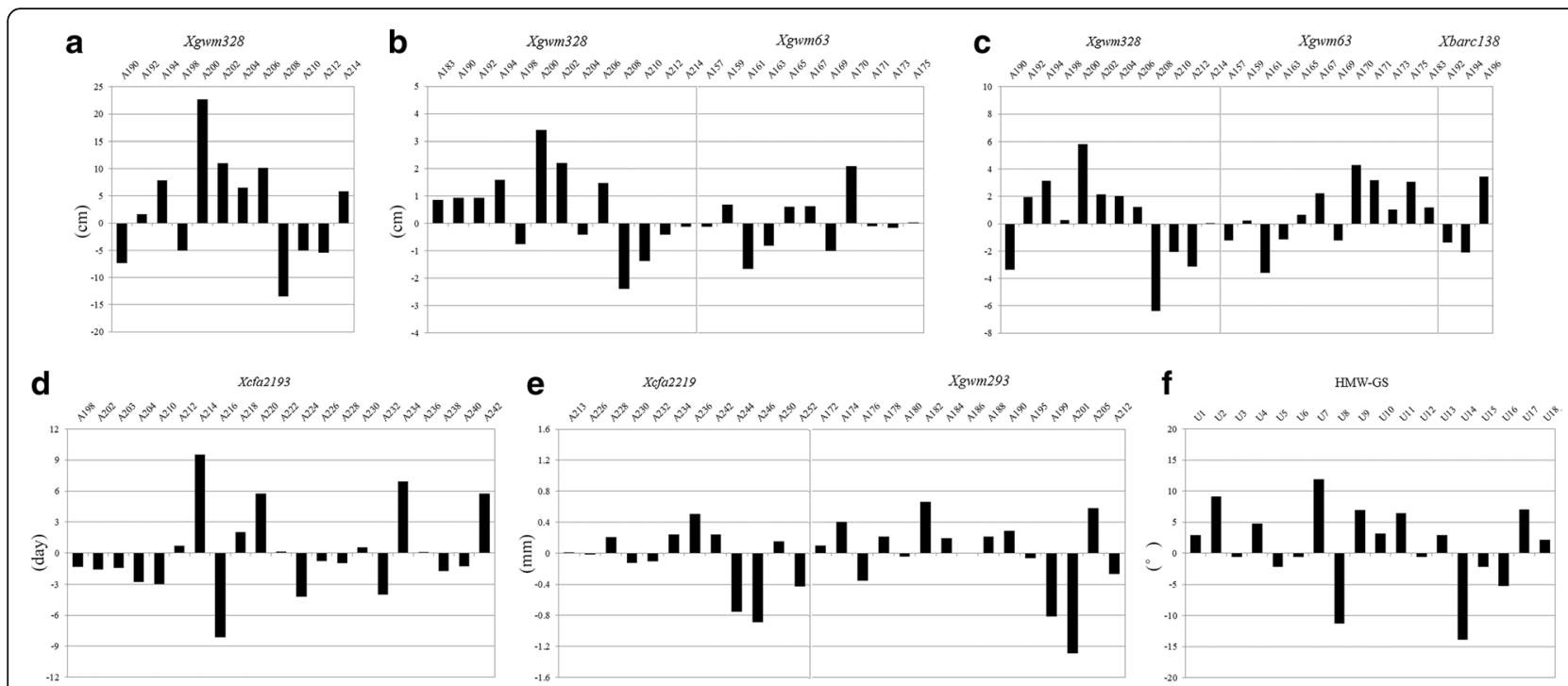

Fig. 6 Phenotypic effect of the marker alleles at Beijing 2014 for loci significantly associated with heading date (a), spike length (b), spikelet number per spike (c), plant height (d), grain length (e) and tiller angle (f)

For example, $\mathrm{PH}$ showed a broad variation with an average of $112.43 \mathrm{~cm}$ ranging from $86.10 \mathrm{~cm}$ to $149.10 \mathrm{~cm}$. All these data demonstrated that the collection of $T$. urartu possessed high genetic variation, which make them suitable for mining valuable genes based on association mapping.

\section{Genetic relationships and population structure}

T. urartu species are endemic to the major geographic regions of the Fertile Crescent $[61,62]$. In our study, the UPGMA dendrogram divided the diverse panel into two major subpopulations consistent with their geographic origin and ecological distribution (Fig. 1). The accessions from Eastern Mediterranean coast belonged to Clusters I, spreading from Lebanon to Jordan, of where the climate was described as poor rainfall and low temperature [63]. The levels of population differentiation in the Bekaa valley of Lebanon, southwestern Syria and the plains alongside Jordan River were low owing to high degrees of gene flow, occasional migration and crosspollination among these accessions [15]. The other possibility is that Lebanese, southwestern Syrian and Jordan populations most probably originated from the same ancestral population, which could be inferred from the rare alleles shared by multiple loci in this study. The rest of accessions from Mesopotamia and Transcaucasia belonged to Clusters II, including Turkey, Iraq, Iran, Armenia and northern Syria. Of them, most Turkish accessions collected along the east-west road from Nusaybin to Viransehir, were in the area of South Eastern Anatolian basin characterized as mild winter and warm-dry summer [64]. The Iranian samples, located in the Zagros mountain range with a similar climatic environment, were also included in the same branch of phylogenetic tree. Other places, such as Urfa, Gaziantep and Mus of Turkey, northern Syria and part of Iraq, had a continental cold and long winter with mild summer-dry climate [64], thus, these T. urartu accessions were grouped together. Specially, populations originated from Armenian, Nusaybin east of Turkey and Malikiyah of northern Syria exhibited high frequencies for the rare alleles such as 127-bp at Xgwm614-2A and 214-bp at Xcfa2193-3A, which separated the populations from other regions. The restricted distribution of these alleles indicated that variation at the associated loci possibly has some adaptive significance, which was supported by previous report [14]. On the whole, genetic differentiation among the accessions was also clearly demonstrated by the first and the second principal coordinates (Fig. 4).

In order to avoid distortion of the relationships among members and the spurious association mapping between phenotype and genotype, we examined population structure of the representative $T$. urartu collection used in this study. The result separated these accessions into Eastern Mediterranean coastal and Mesopotamia-Transcaucasia populations, generally in agreement with the phylogenetic tree and PCoA analysis. However, the loss of genetic diversity and decrease of population size were detected from Cluster II to Cluster I, since bottleneck and genetic drift may generate in the duration of natural selections. Given the subdivision, accessions from Turkey and northern Syria exhibited higher diversity than others, which had also been reported previously $[15,51]$, and huge genetic variations were subsequently emerged among different originated populations. Our results provided inspirations for preservation and sampling of natural T. urartu populations in these regions. 


\section{Marker-trait associations}

Agronomic traits such as PH, HD, SPL and TA play important roles in wheat life cycle and environment adaptability, which are closely associated with the yield potential $[19,65]$. Grain shape, as specified by GL, GW and GLW, is a crucial determinant of grain appearance quality and grain weight in wheat [66]. Therefore, these quantitative traits have drawn major attention in the process of wheat breading over the world. Compared to traditional QTL mapping, association mapping is less time-consuming as no segregating population needs to be developed and no segregating offspring needs to be grown [25]. Under such circumstances, a number of marker-trait associations have already been identified for significant meta-QTLs in bread wheat [67-70]. Nevertheless, a genome-wide association mapping study of agronomic traits based on elite diploid wheat germplasm is still lacking. In this study, six SSR and HMW-GS markers were detected to be highly associated with six agronomic and grain shape related traits in $T$. urartu (Table 5). The Xcfa2193-3A on chromosome 3A associated with $\mathrm{HD}$ explained $>35.41 \%$ of phenotypic variation in four environments, which had also been reported in common wheat [71]. Xgwm328-2A and Xgwm63-7A associated with SPL/SPLN in our study appeared to increase both SPL and SPLN in common wheat [72, 73]. As for GL, we also detected a closely associated SSR marker Xcfa2219-1A, which had been reported to locate in an additive-effect QTL controlling GL in common wheat [74]. Xgwm293 on chromosome 5A was recently characterized associated with GL and TKW in a doubled haploid (DH) mapping population [75]. Moreover, Xbarc138-4A for SPLN was associated with yellow rust in ITMI-mapping population [76]. The data demonstrated that these genetic regions may be conservative between $T$. urartu and hexaploid wheat, and T. urartu could be explored in underlying gene characterization through mapping based cloning for its relative simple genome [5]. Interestingly, the marker of HMW-GSs showed a significant association with TA after the correction of FDR. In this case, the U7 pattern containing only one $1 \mathrm{Ax}$ subunit was associated with the erect type, whereas the U14 pattern containing both 1Ax and 1Ay subunits was associated with the prostrate type. However, the common wheat varieties rarely express 1 Ay subunit and tend to develop an erect plant, this differentiation may be due to the evolution and domestication from $T$. urartu to hexaploid wheat.

Except the phenotypic traits mentioned above, the A genome of wheat is also known to contain QTLs or genes affecting other agronomic traits, heat and drought tolerance, pathogen resistance and so on [77-79]. The allelic variation between $T$. urartu and T. aestivum indicates the great potential for discovery and utilization of wild diploid relatives in wheat breeding. The associations determined in this study would be very useful for marker-assisted selection (MAS) in wheat breeding programs, although more effort is needed to validate these associations in other populations. Along with the progress and wide applications of comparative genomics approaches, further work to elucidate the genetic basis of complex traits will be accelerated.

\section{Conclusion}

Genetic diversity and population structure of $238 \mathrm{~T}$. urartu accessions were analyzed through SSR and HMWGS markers and their associations with phenotypes were detected. Six markers, associated with HD, PH, SPL, SPLN, TA and GL were determined, which should be beneficial to effectively exploit new genetic variations of the wild diploid T. urartu in yield and quality improvement of common wheat using MAS programs. Our results also provide further insights into conservation and future utilization of wild wheat resources.

\section{Additional files}

Additional file 1: Table S1. T. urartu accessions used in the present.
Table S2. List of SSR primers used for genetic diversity and association
analysis. Table S3. Correlations coefficients for the investigated traits of
238 T. urartu accessions in six environments. Table S4. Details of
phenotypic performances and ANOVA analysis of differences between
the Eastern Mediterranean coastal and Mesopotamia-Transcaucasia
groups. Table S5. Correlation coefficients between the investigated traits
in 238 T. urartu accessions in six environments. Table S6. Summary
of Hardy-Weinberg equilibrium testing for SSR markers used in this
study. (DOCX $75 \mathrm{~kb}$ )
Additional file 2: Figure S1. Optimization of the number of
subpopulations ( $\mathrm{K}$ value) for 238 T. urartu accessions by the method of
Delta K (Evanno et al. 2005). The peak represents the appropriate number
of subpopulations. (TIFF $311 \mathrm{~kb}$ )

\section{Abbreviations}

Ae: Number of expected alleles per locus; AFLP: Amplified fragment length polymorphism; AMOVA: Analysis of Molecular Variance; Ao: Number of observed alleles per locus; CTAB: Cetyl trimethyl ammonium bromide; FDR: False discovery rate; GD: Nei's Gene diversity; GL: Grain length;

GLM: General linear model; GLW: Grain length/width ratio; GW: Grain width; HD: Heading date; He: Expected heterozygosity; HMW-GS: High-molecularweight glutenin subunit; Ho: Observed heterozygosity; I: Shannon's information index; MAS: Marker-assisted selection; MLM: Mixed linear model; PCoA: Principal coordinate analysis; PH: Plant height; PIC: Polymorphic information content; QTL: Quantitative trait locus or loci; RAPD: Random amplified polymorphic DNA; RFLP: Restriction fragment length polymorphism; SDS-PAGE: Sodium dodecyl sulfate polyacrylamide gel electropheresis; SPL: Spike length; SPLN: Spikelet number per spike; SSR: Simple sequence repeat; TA: Tiller angle; TGW: Thousand-grain weight; UPGMA: Unweighted pair-group method with arithmetic means

\section{Acknowledgments}

We thank Dr. Shancen Zhao (BGI-Shenzhen) for his critical review.

\section{Availability of data and materials}

The datasets used and/or analysed in the current study are available from the corresponding author on request. The UPGMA tree was deposited in TreeBASE (http://treebase.org) under the following URL: http://purl.org/ phylo/treebase/phylows/study/TB2:S21142. 


\section{Funding}

This research was financially supported by the Ministry of Science and Technology of China (2014CB138101) and the Chinese Academy of Sciences (XDA08010104).

\section{Authors' contributions}

XW carried out most experiments and analyzed the data. XW, DL and WY wrote the manuscript. GL and JS run the SDS-PAGE and analyze the data. JS, $K Z$ and $Y L$ carried out the field experiments, collected the phenotypic data and analyze the data. AZ and DL co-designed the experiments and revised the manuscript. All authors read and approved the final manuscript.

\section{Competing interests}

The authors declare that they have no competing interests.

\section{Consent for publication}

Not applicable.

\section{Ethics approval and consent to participate}

Not applicable.

\section{Publisher's Note}

Springer Nature remains neutral with regard to jurisdictional claims in published maps and institutional affiliations.

\begin{abstract}
Author details
${ }^{1}$ State Key Laboratory of Plant Cell and Chromosome Engineering, National Center for Plant Gene Research, Institute of Genetics and Developmental Biology, Chinese Academy of Sciences, 1 West Beichen Road, Chaoyang District, Beijing 100101, China. ${ }^{2}$ University of Chinese Academy of Sciences, Beijing 100049, China. ${ }^{3}$ College of Agronomy/The Collaborative Innovation Center of Grain Crops in Henan, Henan Agricultural University, No. 95 Wenhua Road, Zhengzhou 450002, China.
\end{abstract}

Received: 23 February 2017 Accepted: 14 June 2017

Published online: 01 July 2017

\section{References}

1. Curtis T, Halford NG. Food security: the challenge of increasing wheat yield and the importance of not compromising food safety. Ann Appl Biol. 2013; 164(3):354-72.

2. Gupta PK, Mir RR, Mohan A, Kumar J. Wheat genomics: present status and future prospects. Int J Plant Genome. 2008;2008:896451.

3. Brenchley R, Spannagl M, Pfeifer M, Barker GL, D'Amore R, Allen AM, et al. Analysis of the bread wheat genome using whole-genome shotgun sequencing. Nature. 2012;491(7426):705-10.

4. Dvořák J, Terlizzi PD, Zhang HB, Resta P. The evolution of polyploid wheats: identification of the a genome donor species. Genome. 1993;36(1):21-31.

5. Ling HQ, Zhao SC, Liu DC, Wang JY, Sun H, Zhang C, et al. Draft genome of the wheat A-genome progenitor Triticum urartu. Nature. 2013;496:87-90.

6. Kimber $G$, Sears ER. Evolution in the genus Triticum and the origin of cultivated wheat. In: Heyne EG, editor. Wheat and Wheal Improvement. Madison: American Society of Agronomy; 1987. p. 154-64.

7. Peng JH, Sun DF, Nevo E. Domestication evolution, genetics and genomics in wheat. Mol Breeding. 2011;28(3):281-301.

8. Reif JC, Gowda M, Maurer HP, Longin CFH, Korzun V, Ebmeyer E, et al. Association mapping for quality traits in soft winter wheat. Theor Appl Genet. 2011;122(5):961-70.

9. Qiu YC, Zhou RH, Kong XY, Zhang SS, Jia JZ. Microsatellite mapping of a Triticum urartu Tum. Derived powdery mildew resistance gene transferred to common wheat (Triticum aestivum L.). Theor Appl Genet. 2005;111(8):1524-31.

10. Rouse MN, Jin Y. Stem rust resistance in A-genome diploid relatives of wheat. Plant Dis. 2011;95(8):941-4.

11. Guzmán C, Alvarez JB. Molecular characterization of a novel waxy allele (Wx-Au1a) from Triticum urartu Thum. Ex Gandil. Genet Resour Crop Ev. 2012;59(6):971-9.

12. Vierling RA, Nguyen HT. Use of RAPD markers to determine the genetic diversity of diploid wheat genotypes. Theor Appl Genet. 1992:84(7):835-8.

13. Dhaliwal HS, Sidhu JS, Minocha JL. Genetic diversity in diploid and hexaploid wheats as revealed by RAPD markers. Crop Improv. 1993; 20:17-20.
14. Castagna R, Gnocchi S, Perenzin M, Heun M. Genetic variability of the wild diploid wheat Triticum urartu revealed by RFLP and RAPD markers. Theor Appl Genet. 1997;94(3):424-30.

15. Moghaddam M, Ehdaie B, Waines JG. Genetic diversity in populations of wild diploid wheat Triticum urartu tum. Ex. gandil. Revealed by isozyme markers. Genetic Res Crop Ev. 2000:47(3):323-34.

16. Baum BR, Bailey LG. Genetic diversity in the red wild einkorn: T. urartu gandilyan (Poaceae: Triticeae). Genetic Resour Crop Ev. 2013;60(1):77-87.

17. Breseghello F. Sorrells ME association mapping of kernel size and milling quality in wheat (Triticum aestivum L.) cultivars. Genetics. 2006;172:1165-77.

18. Risch N, Merikangas $\mathrm{K}$. The future of genetic studies of complex human diseases. Science. 1996;273(5281):516-1517.

19. Kato K, Miura H, Sawada S. Mapping QTLs controlling grain yield and its components on chromosome 5A of wheat. Theor Appl Genet. 2000;101(7): 1114-21.

20. Gegas VC, Nazari A, Griffiths S, Simmonds J, Fish L, Orford S, et al. A genetic frame work for grain size and shape variation in wheat. Plant Cell. 2010; 22(4):1046-56.

21. Sun X, Marza F, Ma H, Carver BF, Bai G. Mapping quantitative trait loci for quality factors in an inter-class cross of US and Chinese wheat. Theor Appl Genet. 2010;120(5):1041-51.

22. Okamoto Y, Nguyen AT, Yoshioka M, lehisa JC, Takumi S. Identification of quantitative trait loci controlling grain size and shape in the $D$ genome of synthetic hexaploid wheat lines. Breeding Sci. 2013;63(4):423-9.

23. Williams K, Munkvold J, Sorrells M. Comparison of digital image analysis using elliptic Fourier descriptors and major dimensions to phenotype seed shape in hexaploid wheat (Triticum aestivum L.). Euphytica. 2013;190(1):99-116.

24. Yu K, Liu DC, Wu WY, Yang WL, Sun JZ, Li X, et al. Development of an integrated linkage map of einkorn wheat and its application for QTL mapping and genome sequence anchoring. Theor Appl Genet. 2017; 130(1):53-70.

25. Addington J, Cornblatt BA, Cadenhead KS, Cannon TD, McGlashan TH, Perkins DO, et al. At clinical high risk for psychosis: outcome for nonconverters. Am J Psy. 2011;168(8):800-5.

26. Li H, Peng ZY, Yang XH, Wang WD, Fu JJ, Wang JH, et al. Genome-wide association study dissects the genetic architecture of oil biosynthesis in maize kernels. Nat Genet. 2012;45(1):43-50.

27. Ding JQ, Ali F, Chen GS, Li HH, Mahuku G, Yang N, et al. Genome-wide association mapping reveals novel sources of resistance to northern corn leaf blight in maize. BMC Plant Biol. 2015;15(1):206.

28. Huang $X H$, Zhao $Y$, Wei $X H$, Li CY, Wang AH, Zhao Q, et al. Genome-wide association study of flowering time and grain yield traits in a worldwide collection of rice germplasm. Nat Genet. 2012;44(1):32-9.

29. Morris GP, Ramu P, Deshpande SP, Hash CT, Shah T, Upadhyaya HD, et al. Population genomic and genome-wide association studies of agroclimatic traits in sorghum. Proc Natl Acad Sci. 2013;110(2):453-8.

30. Zhou ZK, Yu J. Z heng W, Gou ZH, Lyu J, Li WY, et al. Resequencing 302 wild and cultivated accessions identifies genes related to domestication and improvement in soybean. Nat Biotech. 2015;33(4):408-14.

31. Mizumoto K, Hirosawa S, Nakamura C, Takumi S. Nuclear and chloroplast genome genetic diversity in the wild einkorn wheat, Triticum urartu, revealed by AFLP and SSLP analyses. Hereditas. 2002;137(3):208-14.

32. Kulwal PL, Kumar N, Gaur A, Khurana P, Khurana JP, Tyagi AK, et al. Mapping of a major QTL for pre-harvest sprouting tolerance on chromosome $3 \mathrm{~A}$ in bread wheat. Theor Appl Genet. 2005:111(6):1052-9.

33. Saghai-Maroof MA, Soliman KM, Jorgensen RA, Allard RW. Ribosomal DNA spacer-length polymorphisms in barley: Mendelian inheritance, chromosomal location, and population dynamics. Proc Natl Acad Sci. 1984; 81(24):8014-8

34. Schuelke M. An economic method for the fluorescent labeling of PCR fragments. Nature Biotech. 2000;18(2):233-4.

35. Singh SP, Gutierrez JA, Molina A, Urrea C, Gepts P. Genetic diversity in cultivated common bean: II. Marker-based analysis of morphological and agronomic traits. Crop Sci. 1991;31(1):23-9.

36. Payne PI, Lawrence GJ. Catalogue of alleles for the complex gene loci, Glu-A1, Glu-B1, and Glu-D1 which code for high-molecular-weight subunits of glutenin in hexaploid wheat. Cereal Res Commun. 1983; 11(1):29-35.

37. Yeh FC, Yang RC, Boyle T. POPGENE Version 1.32, Microsoft Window-based freeware for population genetic analysis. Molecular Biology and Biotechnology Centre, University of Alberta, Canada, 1999. 
38. Van OC, Hutchinson WF, Wills DPM, Shipley P. MICRO-CHECKER: software for identifying and correcting genotyping errors in microsatellite data. Mol Ecol Notes. 2004;4(3):535-8.

39. Rohlf FJ. NTSYS-PC, numerical taxonomy system for the PC ExeterSoftware, version 2.1. Setauket USA: Applied Biostatistics Inc; 2000.

40. Pritchard JK, Stephens M, Donnelly P. Inference of population structure using multilocus genotype data. Genetics. 2000;155(2):945-59.

41. Evanno G, Regnaut S, Goudet J. Detecting the number of clusters of individuals using the software STRUCTURE: a simulation study. Mol Ecol. 2005;14(8):2611-20.

42. Jakobsson M, Rosenberg NA. CLUMPP: a cluster matching and permutation program for dealing with label switching and multimodality in analysis of population structure. Bioinformatics. 2007;23(14):1801-6.

43. Zanetti E, Marchi MD, Dalvit C, Cassandro M. Genetic characterization of local italian breeds of chickens undergoing in situ conservation. Poultry Sci. 2010;89(3):420-7.

44. Peakall ROD, Smouse PE. GENALEX 6: genetic analysis in excel. Population genetic software for teaching and research. Mol Ecol Notes. 2006;6(1):88-295.

45. Hardy OJ, Vekemans X. SPAGeDi: a versatile computer program to analyse spatial genetic structure at the individual or population levels. Molecul Ecol Notes. 2002;2(4):618-20.

46. Bradbury PJ, Zhang Z, Kroon DE, Casstevens TM, Ramdoss Y, Buckler ES. TASSEL: software for association mapping of complex traits in diverse samples. Bioinformatics. 2007;23(19):2633-5.

47. Gupta P, Balyan H, Edwards K, Isaac P, Korzun V, Röder MS, et al. Genetic mapping of 66 new microsatellite (SSR) loci in bread wheat. Theor Appl Genet. 2002;105(2):413-22.

48. Song QJ, Shi JR, Singh S, Fickus EW, Costa JM, Lewis J, et al. Development and mapping of microsatellite (SSR) markers in wheat. Theor Appl Genet. 2005:110(3):550-60.

49. Periyannan S, Bansal U, Bariana H, Deal K, Luo MC, Dvorak J, et al Identification of a robust molecular marker for the detection of the stem rust resistance gene $\mathrm{Sr} 45$ in common wheat. Theor Appl Genet. 2013;127(4):947-55.

50. Bai JR, Liu KF, Jia X, Wang DW. An analysis of homoeologous microsatellites from Triticum urartu, and Triticum monococcum. Plant Sci. 2004;166(2):341-7.

51. Hammer K, Filatenko AA, Korzun V. Microsatellite markers - a new tool for distinguishing diploid wheat species. Genet Resour Crop Ev. 2000;47(5):497-505.

52. Ren J, Chen L, Sun DK, You FM, Wang JR, Peng YL, et al. SNP-revealed genetic diversity in wild emmer wheat correlates with ecological factors. BMC Evol Biol. 2013;13(1):1-15

53. Huang $X Q$, Börner A, Röder MS, Ganal MW. Assessing genetic diversity of wheat (Triticum aestivum, L.) germplasm using microsatellite markers. Theor Appl Genet. 2000;105(5):699-707.

54. Shewry PR, Halford NG, Tatham AS. High molecular weight subunits of wheat glutenin. J Cereal Sci. 1992;15(2):105-20.

55. Shewry PR, Tatham AS, Barro F, Barcelo P, Lazzeri P. Biotechnology of bread making: unraveling and manipulating the multi-protein gluten complex. Bio/Technology. 1995;13(11):1185-90

56. Ciaffi M, Dominici L, Lafiandra D. High molecular weight glutenin subunit variation in wild and cultivated einkorn wheats (Triticum, spp. poaceae). Plant Syst Evol. 1998;209(1):123-37.

57. Luo GB, Zhang XF, Zhang YL, Yang WL, Li YW, Sun JZ, et al. Composition, variation, expression and evolution of low-molecular-weight glutenin subunit genes in Triticum urartu. BMC Plant Biol. 2015:15(1):68.

58. Wan Y, Wang D, Shewry PR, Halford NG. Isolation and characterization of five novel high molecular weight subunit of glutenin genes from Triticum timopheevi and Aegilops cylindrical. Theor Appl Genet. 2002; 104(5):828-39

59. Waines JG, Payne PI. Electrophoretic analysis of the high molecular weight subunits of Triticum monococcum, T. urartu, and the a genome of bread wheat. Theor Appl Genet. 1987;74(1):71-6.

60. Xu LL, Li W, Wei YM, Zheng YL. Genetic diversity of HMW glutenin subunits in diploid, tetraploid and hexaploid triticum species. Genetic Resour Crop Ev. 2009;56(3):377-91.

61. Johnson BL. Identification of the apparent B-genome donor of wheat. Can J Genet Cyto. 1975;17(1):21-39.

62. Heun M, Haldorsen S, Vollan K. Reassessing domestication events in the near east: einkorn and Triticum urartu. Genome. 2008;51(6):444-51.

63. Wright HE Jr. The environmental setting for plant domestication in the near east. Science. 1976;194(4263):385.
64. Firat $A E$, Tan A. Ecogeography and distribution of wild cereals in Turkey. In: Zencirci N, Kaya Z, Anikster Y, Adams WT, editors. The Proceedings of International Symposium on In situ Conservation of Plant Genetic Diversity. Ankara: Central Research Institute for Field Crops Publication; 1998. p. 81-6.

65. Maccaferri M. Quantitative trait loci for grain yield and adaptation of durum wheat (Triticum durum Desf.) across a wide range of water availability. Genetics. 2008;178(1):489-511.

66. Ramya P, Chaubal A, Kulkarni K, Gupta L, Kadoo N, Dhaliwal HS, et al. QTL mapping of 1000-kernel weight, kernel length, and kernel width in bread wheat (Triticum aestivum L.). J Appl Genet. 2010;51(4):421-9.

67. Breseghello F, Finney PL, Gaines C, Andrews L, Tanaka J, Penner G, et al. Genetic loci related to kernel quality differences between a soft and a hard wheat cultivar. Crop Sci. 2005;45(5):1685-95.

68. Neumann K, Kobiljski B, Denčić S, Varshney RK, Börner A. Genome-wide association mapping: a case study in bread wheat (Triticum aestivum L.) Mol Breeding. 2011;27(1):37-58.

69. Reif JC, Zhang P, Dreisigacker S, Warburton ML, van Ginkel M, Hoisington D, et al. Wheat genetic diversity trends during domestication and breeding. Theor Appl Genet. 2005;110(5):859-64.

70. Wang GM, Leonard JM, von Zitzewitz J, Peterson CJ, Ross AS, Riera-Lizarazu O. Marker-trait association analysis of kernel hardness and related agronomic traits in a core collection of wheat lines. Mol Breeding. 2014 34(1):177-84.

71. Francki MG, Shankar M, Walker E, Loughman R, Golzar H, Ohm H. New quantitative trait loci in wheat for flag leaf resistance to Stagonospora nodorum blotch. Phytopathology. 2011;101(11):1278-84.

72. Heidari B, Sayedtabatabaei BE, Saeidi G, Kearsey M, Suenaga K. Mapping QTL for grain yield, yield components, and spike features in a doubled haploid population of bread wheat. Genome. 2011;54(6):517-27.

73. Li WL, Nelson JC, Chu CY, Shi LH, Huang SH, Liu DJ. Chromosomal locations and genetic relationships of tiller and spike characters in wheat. Euphytica. 2002;125(3):357-66.

74. Li MX, Wang ZL, Liang ZY, Shen WN, Sun FL, Xi YJ, et al. Quantitative trait loci analysis for kernel-related characteristics in common wheat (L.). Crop Sci. 2015;55(4):1485-93.

75. Brinton J, Simmonds J, Minter F, Leverington-Waite M, Snape J, Uauy C. Increased pericarp cell length underlies a major quantitative trait locus for grain weight in hexaploid wheat. New Phytol. 2017. doi:10.1111/nph.14624.

76. Kumar A, Chhuneja P, Jain S, Kaur S, Balyan HS, Gupta PK, et al. Mapping main effect QTL and epistatic interactions for leaf rust and yellow rust using high density itmi linkage map. Australian J Crop Sci. 2013;7(4):492-9.

77. Yahiaoui N, Srichumpa P, Dudler R, Keller B. Genome analysis at different ploidy levels allows cloning of the powdery mildew resistance gene Pm3b from hexaploid wheat. Plant J. 2004:37(4):528-38.

78. Pinto RS, Reynolds MP, Mathews KL, McIntyre CL, Olivares-Villegas JJ, Chapman SC. Heat and drought adaptive QTL in a wheat population designed to minimize confounding agronomic effects. Theor Appl Genet. 2010:121(6):1001-21.

79. Zhang LY, Liu DC, Guo XL, Yang WL, Sun JZ, Wang DW, et al. Genomic distribution of quantitative trait loci for yield and yield-related traits in common wheat. J Integr Plant Biol. 2010;52(11):996-1007.

\section{Submit your next manuscript to BioMed Central and we will help you at every step:}

- We accept pre-submission inquiries

- Our selector tool helps you to find the most relevant journal

- We provide round the clock customer support

- Convenient online submission

- Thorough peer review

- Inclusion in PubMed and all major indexing services

- Maximum visibility for your research

Submit your manuscript at www.biomedcentral.com/submit 